\title{
Downregulated LRRK2 gene expression inhibits proliferation and migration while promoting the apoptosis of thyroid cancer cells by inhibiting activation of the JNK signaling pathway
}

\author{
ZHENG-CAI JIANG ${ }^{1}$, XIAO-JUN CHEN ${ }^{2}$, QI ZHOU ${ }^{2}$, XIAO-HUA GONG ${ }^{2}$, XIONG CHEN $^{2}$ and WEN-JUN WU ${ }^{2}$ \\ ${ }^{1}$ Department of General Surgery, The Second Affiliated Hospital of Wenzhou Medical University, \\ Wenzhou, Zhejiang 325000; ${ }^{2}$ Department of Endocrinology, The First Affiliated Hospital \\ of Wenzhou Medical University, Wenzhou, Zhejiang 325015, P.R. China
}

Received March 13, 2018; Accepted April 1, 2019

DOI: $10.3892 /$ ijo.2019.4816

\begin{abstract}
Emerging studies have indicated that leucine-rich repeat kinase 2 (LRRK2) is associated with thyroid cancer (TC). The present study investigated the effect of LRRK2 on the cell cycle and apoptosis in TC, and examined the underlying mechanisms in vitro. To screen TC-associated differentially expressed genes, gene expression microarray analysis was conducted. Retrieval of pathways associated with TC from the Kyoto Encyclopedia of Genes and Genomes database indicated that the c-Jun N-terminal kinase (JNK) signaling pathway serves an essential role in TC. SW579, IHH-4, TFC-133, TPC-1 and Nthy-ori3-1 cell lines were used to screen cell lines with the highest and lowest LRRK2 expression for subsequent experiments. The two selected cell lines were transfected with pcDNA-LRRK2, or small interfering RNA against LRRK2 or SP600125 (a JNK inhibitor). Subsequently, flow cytometry, terminal deoxynucleotidyl transferase-mediated dUTP-biotin nick end labeling, a 5-ethynyl-2'-deoxyuridine assay and a scratch test was conducted to detect the cell cycle distribution, apoptosis, proliferation and migration, respectively, in each group. The LRRK2 gene was determined to be elevated in TC based on the microarray data of the GSE3678 dataset. The SW579 cell line was identified to exhibit the highest LRRK2 expression, while IHH-4 cells exhibited the lowest LRRK2 expression. LRRK2 silencing, through inhibiting the activation of the JNK signaling pathway, increased the expression levels of genes and proteins associated with cell cycle arrest
\end{abstract}

Correspondence to: Dr Xiao-Hua Gong or Dr Wen-Jun Wu, Department of Endocrinology, The First Affiliated Hospital of Wenzhou Medical University, Nanbaixiang Street, Wenzhou, Zhejiang 325015, P.R. China

E-mail: xiao_huagong@yeah.net

E-mail:wwju127@163.com

Key words: leucine-rich repeat kinase 2, c-Jun N-terminal kinase signaling pathway, cell cycle arrest, proliferation, apoptosis, migration, thyroid cancer and apoptosis in TC cells, promoted cell cycle arrest and apoptosis, and inhibited cell migration and proliferation in TC cells, indicating that LRRK2 repression could exert beneficial effects through the JNK signaling pathway on TC cells. These observations demonstrate that LRRK2 silencing promotes TC cell growth inhibition, and facilitates apoptosis and cell cycle arrest. The JNK signaling pathway may serve a crucial role in mediating the anti-carcinogenic activities of downregulated LRRK2 in TC.

\section{Introduction}

As a common endocrine-associated malignancy, thyroid cancer (TC) typically arises from thyroid nodules, which can be detected by palpation and imaging in adults, particularly in the elderly $(1,2)$. TC with different cellular origins, characteristics and prognoses possess different histological types and subtypes (3). There are numerous risk factors for $\mathrm{TC}$, including ionizing radiation exposure, a history of benign thyroid disease and a family history of TC (4-6). TC has been reported to account for $1.0-1.5 \%$ of new cancer cases diagnosed each year in USA, and its incidence has steadily increased in the last 30 years up to 2013 (7). According to a statistic reported in 2015, TC is the most commonly diagnosed cancer among females who are $>30$ years old in China (8). No notable symptoms occur during the life of the patient with TC; therefore, TC is frequently firstly identified in an autopsy finding (9). TC afflicts patients due to its chronic nature, and patients require life-long medication or monitoring (10). Further effective diagnoses and treatments of TC remain a topic of research $(11,12)$. Gene therapy is considered to be the most promising novel method in the treatment of dire cases of TC and those that do not respond to traditional treatments (13).

The leucine-rich repeat kinase 2 (LRRK2) gene encodes a large protein with a domain such as a Ras complex guanosine triphosphate hydrolase domain and a C-terminal Roc domain (14). The LRRK2 expression has been detected in various regions, including the substantia nigra, putamen, cortex and cerebellum, and has been demonstrated to be responsible for autosomal-dominant Parkinson's disease (PD) (15-18). Furthermore, a previous study reported that LRRK2 is 
overexpressed in TC, and its expression is a relatively specific marker for TC (19). Additionally, as a highly conserved pathway, the c-Jun N-terminal kinase (JNK) signaling pathway functions crucially in regulating gene expression and intracellular metabolism in life activities, including growth and development, apoptosis and cellular response to external stress (20). Recently, the activation of the JNK signaling pathway was reported to mediate thyroid dysfunction re sulting from thyroid inflammatory responses and polychlorinated biphenyls (21). Based on existing knowledge, gene expression microarray analysis was performed to screen differentially expressed genes (DEGs) associated with TC and determine an unclarified gene, LRRK2, associated with TC. Hereby, attempts were undertaken in the present study to investigate the potential association among LRRK2, the JNK signaling pathway and TC in two selected TC cell lines. However, the effect of LRRK2 on human TC cells is vague. In the present study, the potential mechanism of LRRK2 in human TC cells was elucidated from the effects of LRRK2 on the cell cycle and apoptosis of TC cells. An association was determined between LRRK2 and JNK signaling pathways. The present experimental results indicated that LRRK2 affects the cell cycle arrest and apoptosis of TC cells due to its involvement in the JNK signaling pathway.

\section{Materials and methods}

Bioinformatics prediction. The Gene Expression Omnibus (GEO; (https://www.ncbi.nlm.nih.gov/gds/?term=thyroid+ cancer) database was used to retrieve data with 'thyroid cancer' as the keyword, and GSE3678 microarray dataset (22) were selected using GPL570. The annotated probe files included 7 TC samples and 7 healthy control samples. With the significant threshold $(\log 2 \mathrm{FCl}>2, \mathrm{P}<0.05)$, DEGs were selected using the Limma package of R software (version 3.5.1; https://www.r-project.org/). The pheatmap package of $\mathrm{R}$ software was used for thermal map construction, and the expression levels of DEGs were obtained through analysis of variance.

Gene retrieval and protein interaction analysis. With 'thyroid carcinoma' as the keyword, DisGeNET (http://www. disgenet.org/) was used to retrieve 10 genes that were highly associated with the disease for further analysis. Based on the STRING database, protein interaction analysis between DEGs in GSE3678 and 10 genes highly associated with TC was conducted (23-25).

Signaling pathway retrieval. Associated functions of genes and biological metabolic pathways were retrieved through the Kyoto Encyclopedia of Genes and Genomes (KEGG) database (http://www.kegg.jp/kegg/). With 'thyroid cancer' as the keyword and selecting KEGG DISEASE (https://www.kegg. $\mathrm{jp} / \mathrm{kegg} /$ ), the metabolic pathways associated with TC were retrieved. Among them, the mitogen-activated protein kinase metabolic pathway (TC-associated metabolic pathway) was selected for subsequent study.

Cell screening and culture. TFC-133 [differentiated thyroid carcinoma cell line; cat. no. ZK1101 (XR); purchased from Beijing Zhongke Quality Inspection Biotechnology Co., Ltd.,
Beijing, China], SW579 (thyroid squamous cell carcinoma cell), TPC-1 (thyroid papillary carcinoma cell), IHH-4 (thyroid papillary carcinoma cell) and Nthy-ori3-1 (normal thyroid cell line) cell lines were purchased from the Cell Bank of the Shanghai Institute of Biochemistry and Cell Biology, Chinese Academy of Sciences (Shanghai, China). The cells were cultured in RPMI-1640 culture medium (Biopeony, Beijing, China) at $37^{\circ} \mathrm{C}$ in an atmosphere containing $5 \% \mathrm{CO}_{2}$. According to the cell growth conditions, when the cells were spread over $80-90 \%$ of the culture plate, the cells were passaged. The two cell lines with the highest and lowest LRRK2 expression levels were selected for subsequent experiments via reverse transcription-quantitative polymerase chain reaction (RT-qPCR) and western blot analysis according to the subsequent protocols.

Plasmid construction, cell grouping and transfection. According to the known sequences of LRRK2 in the National Center for Biotechnology Information (https://www.ncbi.nlm. nih.gov/nuccore/XM_005268629.4/), negative control (NC), overexpression and three interference sequences (Table I) were constructed by Sangon Biotechnology Co., Ltd. (Shanghai, China), and were synthesized by Shanghai GeneChem Co., Ltd. (Shanghai, China). RT-qPCR and western blot analysis were performed, according to the subsequent protocols, to select an interference sequence with the best interference efficacy following SW579 cell transfection, according to the subsequent protocols, for further usage.

The SW579 and IHH-4 cell lines in the logarithmic growth phase were digested with trypsin and seeded in a 24 -well plate at a cell density of $1 \times 10^{6}$ cells $/ \mathrm{ml}$. The cells were assigned into the blank (transfected with negative plasmids), NC (transfected with unrelated plasmid), pcDNA-LRRK2 (transfected with pcDNA-LRRK2 plasmid), si-LRRK2 [transfected with small interfering (si)RNA against LRRK2], SP600125 (transfected with a JNK inhibitor), and si-LRRK2 and SP600125 (co-transfected with si-LRRK2 plasmid and SP600125 plasmid) groups. These plasmids were provided by Sangon Biotechnology Co. Ltd.

The cells were transfected with Lipofectamine ${ }^{\circledR} 2000$, according to the manufacturer's protocols (cat. no. 11668-019; Invitrogen; Thermo Fisher Scientific, Inc., Waltham, MA, USA). A total of $250 \mu 1$ Option-MEM without serum (cat. no. 51985042; Gibco; Thermo Fisher Scientific, Inc.) was used to dilute 100 pmol plasmids to a final concentration of $50 \mathrm{nM}$, followed by incubation at room temperature for $5 \mathrm{~min}$ with gentle shaking. A total of $250 \mu \mathrm{l}$ Option-MEM without serum was used to dilute $5 \mu \mathrm{l}$ Lipofectamine 2000 , followed by incubation at room temperature for $5 \mathrm{~min}$ with gentle shaking. A mixture of the aforementioned two solutions, following incubation at room temperature for $20 \mathrm{~min}$, was seeded in a culture well at a cell density of $1 \times 10^{6}$ cells/well and cultured for $6-8 \mathrm{~h}$ at $37^{\circ} \mathrm{C}$ in an atmosphere containing $5 \% \mathrm{CO}_{2}$. The medium was replaced with fresh RPMI-1640 complete medium, and the cells were continuously cultured at $37^{\circ} \mathrm{C}$ for $24-48 \mathrm{~h}$ for subsequent experiments.

$R T$ - $q P C R$. miRNeasy Mini kit (cat. no. 217004; Qiagen GmbH, Hilden, Germany) were used to extract total RNA from the two TC cell lines, according to the manufacturer's protocols. Primers 
Table I. Sequences of three siRNA.

\begin{tabular}{ll}
\hline siRNA & \multicolumn{1}{c}{ Sequence (DNA) } \\
\hline si-LRRK2-1 & 5'-TACGTCCAAGGTCGGGCAGGAAGA-3' \\
si-LRRK2-2 & 5'-GCTACTGTTTACTATCAGGCT-3' \\
si-LRRK2-3 & 5'-GGATCTCTCTTCAATTAAT-3' \\
NC & 5'-GTCTGGATGGCTAGGTGA-3'
\end{tabular}

siRNA, small interfering RNA; LRRK2, leucine-rich repeat kinase 2; NC, negative control.

(Table II) were synthesized by Takara Biotechnology Co., Ltd. (Dalian, China). RNA was reverse transcribed into cDNA using PrimeScript RT kit (cat. no. RR036A; Takara Biotechnology Co., Ltd.). The reverse transcription system was conducted as follows: Reverse transcription reaction for $15 \mathrm{~min}$ at $37^{\circ} \mathrm{C}$ (three times) and reverse transcriptase inactivation reaction at $85^{\circ} \mathrm{C}$ for 5 sec. $\mathrm{qPCR}$ was conducted according to the instructions of the SYBR ${ }^{\circledR}$ Premix Ex Taq ${ }^{\mathrm{TM}}$ II kit (cat. no. RR820A; Takara Biotechnology Co., Ltd.). The reaction system $(50 \mu \mathrm{l})$ contained $25 \mu 1$ SYBR Premix Ex Taq II (2X), $2 \mu 1$ forward primer for PCR, $2 \mu \mathrm{l}$ reverse primer for PCR, $1 \mu \mathrm{l}$ OX Reference Dye (50X), $4 \mu \mathrm{l}$ DNA template and $16 \mu \mathrm{l}$ double-distilled $\mathrm{H}_{2} \mathrm{O}$. The ABI 7500 qPCR instrument (cat. no. 7500; Applied Biosystems; Thermo Fisher Scientific, Inc.) was employed for qPCR detection. The qPCR conditions were as follows: Pre-denaturation at $95^{\circ} \mathrm{C}$ for $30 \mathrm{sec}, 40$ cycles of denaturation at $95^{\circ} \mathrm{C}$ for $5 \mathrm{sec}$, and annealing and extension at $60^{\circ} \mathrm{C}$ for $30 \mathrm{sec}$. With $2 \mu \mathrm{g}$ total RNA as the template and GAPDH as the internal reference, the relative mRNA expression of target genes was calculated based on the $2^{-\Delta \Delta \mathrm{Cq}}$ method, $\Delta \Delta \mathrm{Cq}=\left(\mathrm{Cq}_{\text {target gene }}\right.$ in the model group $\left.-\mathrm{Cq}_{\text {reference gene in the model group }}\right)-\left(\mathrm{Cq}_{\text {target gene in the control }}\right.$ group $\left.-\mathrm{Cq}_{\text {reference gene in the control group }}\right)(26)$. The experiment was independently repeated in triplicate.

Western blot analysis. Cells in the logarithmic growth phase were centrifuged at $5,035 \mathrm{x} \mathrm{g}$ for $20 \mathrm{~min}$ at $4^{\circ} \mathrm{C}$. Every $20 \mu \mathrm{l}$, packed cells were added to $100 \mu 1$ lysate and $1 \mu 1$ enzyme inhibitor (cat. no. 1111111; Jiamay Biotech, Ltd., Beijing, China), lysed on ice for $30 \mathrm{~min}$ and centrifuged at $16,000 \mathrm{x} \mathrm{g}$ at $4^{\circ} \mathrm{C}$ for $10 \mathrm{~min}$. Thereafter, the supernatant proteins were extracted for protein quantitative detection using a Coomassie brilliant blue protein assay. A total of $50 \mu \mathrm{g}$ proteins were extracted to be dissolved in 2X SDS sample buffer (Thermo Fisher Scientific, Inc.). Subsequently, the aforementioned samples were transferred to the polyvinylidene fluoride (PVDF) membrane via $10 \%$ SDS-PAGE, followed by blocking with $5 \%$ non-fat milk powder at room temperature for $1 \mathrm{~h}$ and washing 2 times with PBS. Subsequently, the PVDF membrane was cultured overnight at $4{ }^{\circ} \mathrm{C}$ with diluted primary antibodies of mouse anti-human purchased from Abcam (Cambridge, UK), including LRRK2 (1:20,000; cat. no. ab133474), JNK (1:2,000; cat. no. ab124956), phospho(p)-JNK (1:500; cat. no. ab59196), matrix metalloproteinase (MMP-9; 1:5,000; cat. no. ab73734), Cyclin A2 (1:2,000; cat. no. ab181591), Cyclin D1 (1:20,000; cat. no. ab134175), B-cell lymphoma 2 (Bcl-2)-associated X (Bax; 1:5000; cat. no. ab32503), Bcl-2
Table II. Primer sequences for reverse transcription quantitative polymerase chain reaction.

\begin{tabular}{ll}
\hline Gene & \multicolumn{1}{c}{ Primers sequence (5'-3') } \\
\hline LRRK2 & F: GGAATCCCAAACCACTGGACA \\
& R: GGTAGCGTCGTCGTAAAGCACA \\
FNK & R: CAAGCAGTTAGATGAAAGGGAA \\
& F: ACCACGAACCAACCTCAC \\
MMP-9 & R: CACCAAACTGGATGACAATG \\
Fyclin A2 & F: ATGTCACCGTTCCTCCTTG \\
Fyclin D1 & F: CCCTCGGTGTCCTACTTCA \\
& R: CTCCTCGCACTTCTGTTCCT \\
Bax & F: ATGGGCTGGACATTGGAC \\
& R: GGGACATCAGTGGCTTCAGT \\
Bcl-2 & R: CAACACACAGACCCACCCAGA \\
& F: TGGCTTCATACCACAGGTTTC \\
p16 & R: AATGGACATTTACGGTAGTG \\
& F: AAATCTTTGACCTGATTGGG \\
CDK4 & R: CCTTATGTAGATAAGAGTGCTG \\
& F: GGGAAACTGTGGCGTGAT \\
GAPDH & RAGTGGGTGTCGCTGTTGA \\
\hline &
\end{tabular}

LRRK2, leucine-rich repeat kinase 2; JNK, c-Jun N-terminal kinase; MMP-9, matrix metalloproteinase-9; CDK4, cyclin-dependent kinase 4; F, forward; R, reverse; Bcl-2, B-cell lymphoma-2; Bax, Bcl-2-associated X.

(1:1,000; cat. no. ab32124), p16 (1:5,000; cat. no. ab51243), cyclin-dependent kinase 4 (CDK4; 1:5,000; cat. no. ab108357) and GAPDH (1:1,000; cat. no. ab8245). Following washing in TBS with $0.05 \%$ Tween-20 (TBST) three times (5 min each), the membrane was incubated at room temperature for $1 \mathrm{~h}$ with diluted secondary antibodies of goat anti-rat $(1: 100)$ labeled with horseradish peroxidase (cat. no. HA1003; Yan Hui Biological Technology Co., Ltd., Shanghai, China). The membrane was reacted with enhanced chemiluminescence (cat. no. ECL808-25; Biomiga, Inc., San Diego, CA, USA) at room temperature for $1 \mathrm{~min}$. Following discarding the liquids, the membrane was covered with a preservative film, followed by X-ray imaging (cat. no. 36209ES01; Shanghai Qcbio Science \& Technologies Co., Ltd., Shanghai, China) and was observed. Using GAPDH as the internal reference, the relative protein expression was equal to the ratio of target protein bands and internal reference bands. The experiment was independently repeated in triplicate.

5-ethynyl-2'-deoxyuridine (EdU) assay. Cells were incubated in a cell culture plate at a density of $1 \times 10^{6}$ cells $/ \mathrm{ml}$ with EdU solution (Beijing Biolab Technology Co., Ltd., Beijing, China) at room temperature for $2 \mathrm{~h}$ and were washed once with PBS. Thereafter, the cells were fixed with $40 \mathrm{~g} / \mathrm{l}$ polyoxymethylene at room temperature for $30 \mathrm{~min}$, were 
incubated in glycine solution at room temperature for $8 \mathrm{~min}$ and were washed two times with PBS, followed by rinsing with PBS containing 0.5\% Triton X-100. After adding Apollo ${ }^{\circledR}$ staining solution (Shanghai Threebio Technology Co., Ltd., Shanghai, China), cells were incubated avoiding light at room temperature for $30 \mathrm{~min}$ and then were observed under a fluorescence microscope (x400 magnification). EdU-stained cells (proliferating cells) and Hoechst 33342-stained cells (total cells; stained at $37^{\circ} \mathrm{C}$ for $90 \mathrm{~min}$ ) were counted in three fields selected in 400-fold fields as follows: Cell proliferation rate $=($ proliferated cells $/$ total cells $) \times 100 \%$. The experiment was independently repeated in triplicate.

Flow cytometry. After $48 \mathrm{~h}$ of transfection, the cells were collected and reacted with $0.25 \%$ trypsin. The cell density was adjusted to $1 \times 10^{6}$ cells $/ \mathrm{ml}$ in fresh RPMI-1640 complete medium. A total of $1 \mathrm{ml}$ cells was centrifuged at 5,440 x g for $10 \mathrm{~min}$ at $37^{\circ} \mathrm{C}$. Following removal of the supernatant, $1 \mathrm{ml}$ cells was added to $2 \mathrm{ml}$ PBS, followed by centrifugation at $5,440 \mathrm{x} \mathrm{g}$ for $15 \mathrm{~min}$ at $37^{\circ} \mathrm{C}$. The supernatant was discarded, and the cells were fixed overnight at $4^{\circ} \mathrm{C}$ with an addition of $70 \%$ ethanol. The following day, the cells were washed with PBS twice. The cell suspension $(100 \mu \mathrm{l})$ was added to $50 \mu \mathrm{g}$ propidium iodide (PI) containing RNase (cat. no. 40710ES03; Shanghai Qcbio Science \& Technologies Co., Ltd.), avoiding light at room temperature for $30 \mathrm{~min}$, and then was filtered using a nylon mesh with 100 meshes. A flow cytometer (BD Bioscience; Beckman Coulter, Inc., Franklin Lakes, NJ, USA) was employed to record the red fluorescence at an excitation wavelength of $488 \mathrm{~nm}$ to detect the cell cycle distribution.

Annexin V-fluorescein isothiocyanate/PI (FITC/PI) double staining was conducted to detect cell apoptosis. The treated cells were cultured at $37^{\circ} \mathrm{C}$ in an incubator containing $5 \% \mathrm{CO}_{2}$ for $48 \mathrm{~h}$. Subsequently, the cells were collected and washed twice with PBS, followed by centrifugation at 5,053 x g for $10 \mathrm{~min}$ at $37^{\circ} \mathrm{C}$ and suspension in $200 \mu \mathrm{l}$ binding buffer (Shanghai Canspec Scientific Instruments Co., Ltd., Shanghai, China). Following the addition of $10 \mu \mathrm{l}$ Annexin V-FITC (cat. no. ab14085; Abcam) and $5 \mu \mathrm{l}$ PI, the cells were gently mixed and reacted avoiding light at room temperature for $15 \mathrm{~min}$. Following the addition of $300 \mu \mathrm{l}$ binding buffer (Shanghai Canspec Scientific Instruments Co., Ltd.), the flow cytometer (BD Bioscience; Beckman Coulter, Inc.) was used to detect cell apoptosis at an excitation wavelength of $488 \mathrm{~nm}$. The experiment was independently repeated in triplicate.

Scratch test. After $48 \mathrm{~h}$ of transfection, the transfected cells were seeded in a 6 -well plate with $5 \times 10^{5}$ cells/well. When the cell confluence reached $\sim 90 \%$ at room temperature, a thin wound was produced along the center of each well via a $10 \mu \mathrm{l}$ sterile pipette tip. Following removal of floating cells by PBS, the cells continued to be cultured with serum-free medium (LONZA X-VIVO; Shanghai Lianxun Biotech Co., Ltd., Shanghai, China) at room temperature for $0.5-1 \mathrm{~h}$ for restoration. The cells were imaged after 0 and $24 \mathrm{~h}$ of culture (timer started following cell restoration) under a fluorescence microscope (x100 magnification; cat. no. M30C; Shanghai Wanheng Precision Instruments Co., Ltd. Shanghai, China). The cell migration distance was measured using Image-Pro Plus Analysis software 6.0 (Media Cybernetics, Inc., Rockville,
MD, USA). The experiment was independently repeated in triplicate.

Hoechst 33258 staining. A single-cell suspension ( $2 \times 10^{5}$ cells/ml; RPMI-1640 medium) was cultured in a 24-well plate (438 $\mu \mathrm{l} /$ well) with pretreated coverslips at room temperature for $24 \mathrm{~h}$. Subsequently, the medium was replaced, and each culture was set up in a sextuplet manner. A total of $500 \mu 1$ cells were added to RPMI-1640 culture medium, followed by culture at room temperature for $48 \mathrm{~h}$. Thereafter, the cells were stained and mounted according to the manufacturer's protocols. The cells were then observed and imaged under a fluorescence microscope (x400 magnification; cat. no. M30C; Shanghai Wanheng Precision Instrument Co., Ltd.) with an excitation wavelength of $350 \mathrm{~nm}$ and an emission wavelength of $460 \mathrm{~nm}$.

Terminal deoxynucleotidyl transferase-mediated dUTP-biotin nick end labeling (TUNEL). A total of $2 \times 10^{5}$ single cell suspension/ml was inoculated in the 24-well plate with pretreated cover glass and cultured at room temperature for 24 h. Subsequently, the serum-free medium (LONZA X-VIVO was changed, and the cells were fixed with $4 \%$ polyformaldehyde at $4^{\circ} \mathrm{C}$ for $30 \mathrm{~min}$, washed with PBS once, resuspended with PBS $(3: 1,000)$ containing $0.3 \%$ Triton X-100, and incubated at room temperature for $5 \mathrm{~min}$. Cells were stained and mounted with neutral balsam based on the instructions of TUNEL apoptosis detection kit (cat. no. C1088; Beyotime Institute of Biotechnology, Shanghai, China). Subsequently, the cells were observed and imaged under a fluorescence microscope (10 random fields; x400 magnification; cat. no. M30C; Shanghai Wanheng Precision Instruments Co., Ltd.) when the excitation wavelength was $450 \mathrm{~nm}$ and emission wavelength was $565 \mathrm{~nm}$ (green fluorescence).

Sulforhodamine $B(S R B)$ staining. Cells in the logarithmic growth phase were collected and diluted by RPMI-1640 culture medium to $1 \times 10^{6}$ cells/l cell suspension. The suspension was injected into a 96-well plate using a Finnpipette (Thermo Fisher Scientific, Inc.) with $190 \mu \mathrm{l}$ in each well. The cells were then cultured at $37^{\circ} \mathrm{C}$ in an atmosphere containing $5 \% \mathrm{CO}_{2}$, and after 24,48 or $72 \mathrm{~h}$ culturing, $0.1 \mathrm{~g} / 1$ trichloroacetic acid was added to the cells, followed by fixation at $4^{\circ} \mathrm{C}$ for $1 \mathrm{~h}$. The cells were washed with distilled water four times. Subsequently, the cells were air dried at room temperature for $20 \mathrm{~min}$ and then were placed at room temperature for 30 min of culture with $100 \mu \mathrm{lSRB}$ $(0.1 \mathrm{~g} / \mathrm{l}$ containing $0.01 \%$ acetic acid). The cells were washed with $1 \%$ acetic acid four times. After air drying and adding $0.01 \%$ Tris base $(\mathrm{pH} 10.5 ; 10 \mathrm{mmol} / \mathrm{l})$ alkali liquor containing $200 \mu \mathrm{l}$ acetic acid, the cells were mixed with oscillation for 3 min, and the optical density (OD) at $579 \mathrm{~nm}$ was measured. Inhibition effects on cell growth after 24,48 or $72 \mathrm{~h}$ were observed under an inverted microscope (x400 magnification). Cell growth curves were drawn with time points as the abscissa and the OD value as the ordinate.

Trypan blue staining. To examine whether SP600125 (JNK phosphokinase inhibitor) is toxic to cells, trypan blue staining was used. Through trypan blue staining, SP600125 (1 and $10 \mu \mathrm{M})$ was used to treat SW579 cells for $24 \mathrm{~h}$ at $37^{\circ} \mathrm{C}$. Hanks solution (AAPR25-250; Guangzhou Peiyu Biological Products Co., 
Table III. Retrieval of genes associated with thyroid cancer (Top 10).

\begin{tabular}{llrr}
\hline Gene & & \multicolumn{1}{c}{ Gene Name } & PMIDs \\
\hline TG & Thyroglobulin & 0.217 & 53 \\
SLC26A4 & Solute carrier family 26 member 4 & 0.202 & 6 \\
PRKAR1A & Protein kinase cAMP-dependent type I regulatory subunit $\alpha$ & 0.201 & 0.2 \\
KCNJ10 & Potassium voltage-gated channel subfamily J member 10 & 0.2 & 0 \\
FOXI1 & Forkhead box I1 & 0.081 & 170 \\
RET & Ret proto-oncogene & 0.059 & 174 \\
BRAF & B-Raf proto-oncogene, serine/threonine kinase & 0.016 & 58 \\
SLC5A5 & Solute carrier family 5 member 5 & 0.016 & 0.014 \\
TP53 & Tumor protein p53 & 57 \\
BCR & BCR, RhoGEF and GTPase activating protein & 6 \\
\hline
\end{tabular}

Score of the reliability of the gene-disease pair, based on the type and number of sources where is reported, and the number of PMIDs; PMIDs, PubMed Unique Identifiers; total number of PMIDs supporting the association.

A

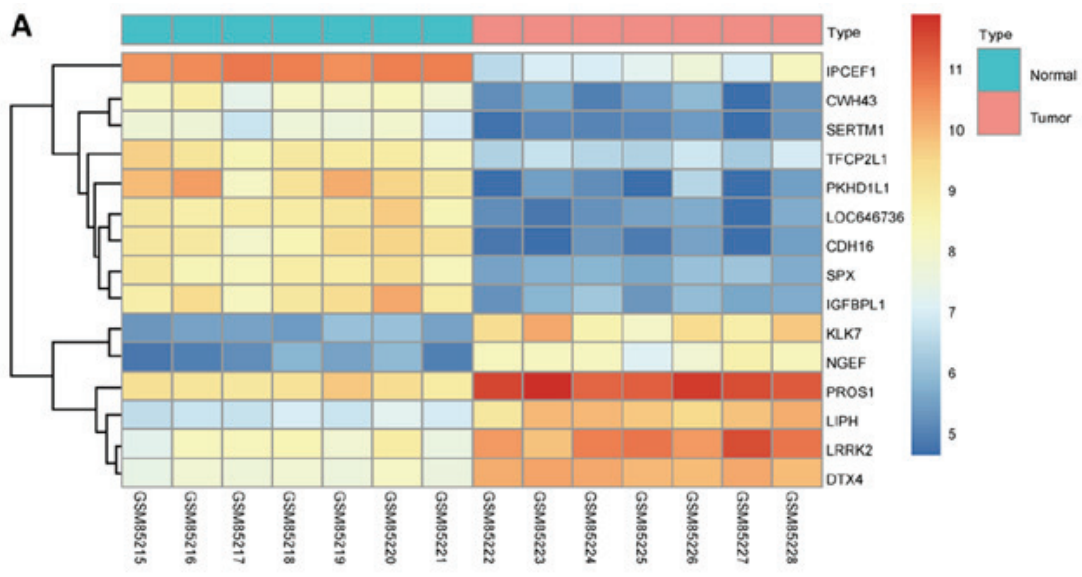

B

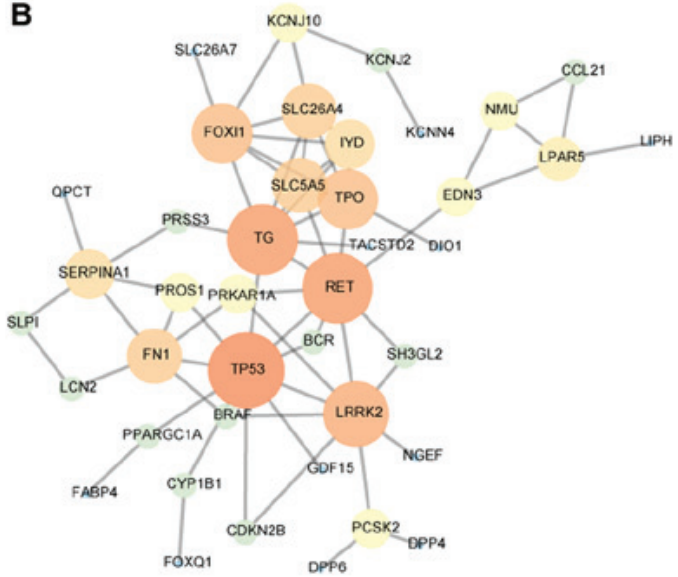

Figure 1. Analysis of the DEGs and metabolic pathways associated with TC cells. (A) Differential expression analysis in the dataset. (B) Protein interaction analysis between 96 DEGs and 10 known genes of TC was conducted using the STRING database. DEGs, differentially expressed genes; TC, thyroid cancer.

Ltd., Guangzhou, China) was used to prepare $0.1 \%$ trypan blue solution. Subsequently, the cultured adherent cells were added with the mixture [0.5\% trypsin: $0.2 \%$ ethylenediaminetetraacetic acid (E8040; Beijing Solarbio Science \& Technology Co., Ltd., Beijing, China); 1:1], and Hanks solution was added to produce cell suspension, and diluted to $1 \times 10^{5} / \mathrm{ml}$. The suspension was added with trypan blue staining solution $(0.1 \mathrm{ml}$ suspension added with a drop of trypan blue staining solution) at room temperature for 3-5 min, placed on a slide, and then observed under a high power inverted microscope (magnification, $\mathrm{x} 40$; Olympus Optical Co., Ltd., Tokyo, Japan).

Statistical analysis. All data were processed by SPSS 21.0 (IBM Corp., Armonk, NY, USA). Measurement data were expressed as the means \pm standard deviation. One-way analysis of variance (ANOVA) was used for comparisons among multiple groups. The normality test of data was performed by the Kolmogorov-Smirnov method, and the post hoc test for the data that were distributed in normality among the groups was conducted by Tukey's multiple comparisons in one-way ANOVA. The cell viability at different time points was analyzed by repeated measurement variance analysis. $\mathrm{P}<0.05$ was considered to indicate a statistically significant difference.

\section{Results}

LRRK2 is an upregulated gene and the JNK signaling pathway is an associated pathway in TC cells by microarray profiling and enrichment analysis. The sequencing dataset associated with TC was retrieved in the GEO database, and the GSE3678 database was selected. Following differential expression analysis in the dataset (Fig. 1A), 96 DEGs were obtained, among which 55 were upregulated and 41 were downregulated in TC samples.

To further understand the pathogenesis of TC, genes associated with TC were retrieved in the DisGeNET database. The first 10 genes with a high association with TC were analyzed (Table III). Protein interaction analysis between 96 differentiated expression genes and 10 known genes of TC was conducted using the STRING database (Fig. 1B). The results demonstrated that genes with a high association 

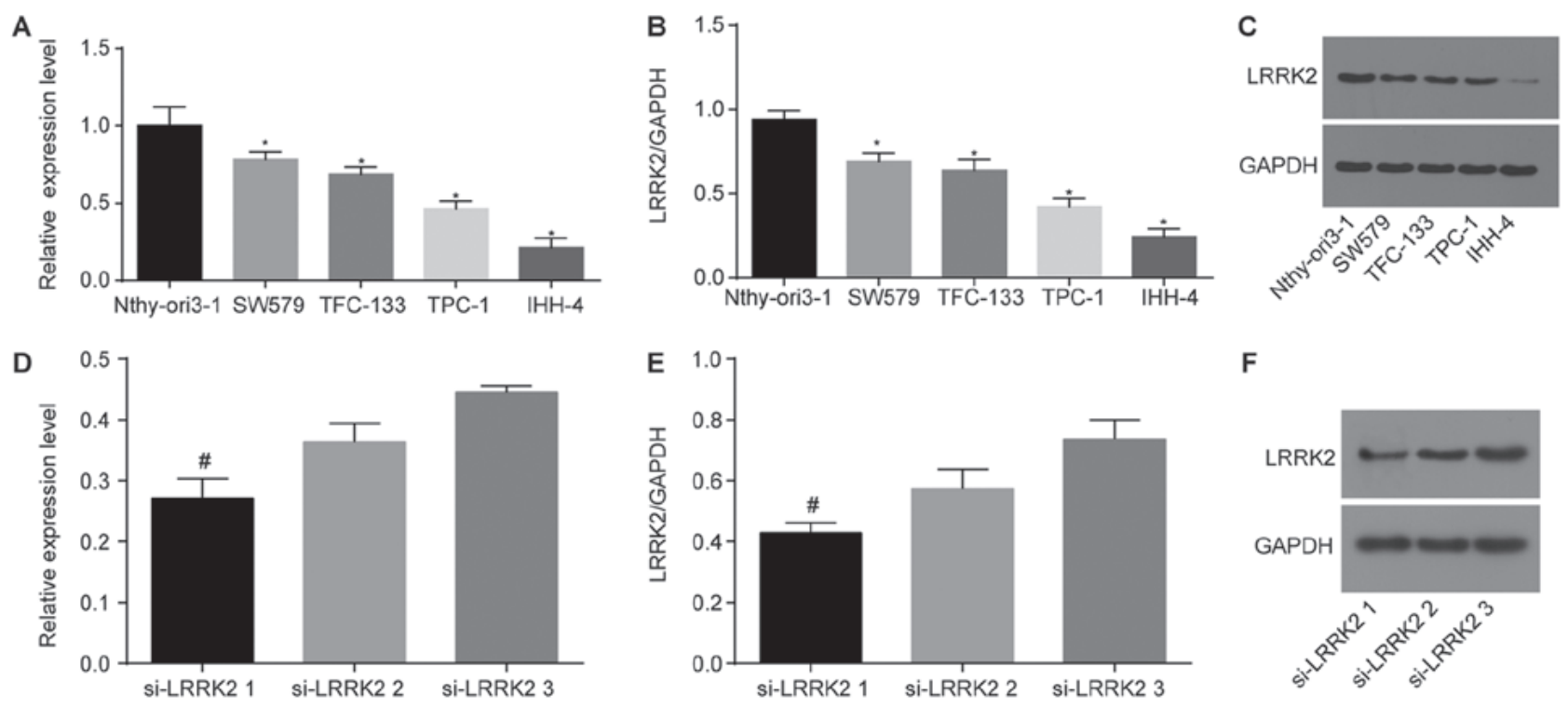

$\mathbf{F}$

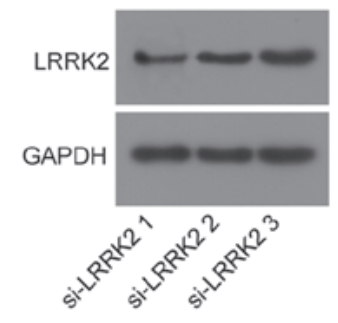

Figure 2. Reverse transcription-quantitative polymerase chain reaction and western blot analysis demonstrated that the SW579 cell line has the highest LRRK2 expression, while the IHH-4 cell line had the lowest, and si-LRRK2-1 exhibited the greatest interference effect on LRRK2 expression. (A) LRRK2 mRNA expression in each group. (B) Determination of LRRK2 protein expression in each group. (C) Protein bands of LRRK2. (D) LRRK2 mRNA expression in si-LRRK2 cells in each group. (E) Determination of LRRK2 protein expression in si-LRRK2 cells in each group. (F) Protein bands of LRRK2 in si-LRRK2 cells. The experiment was independently repeated in triplicate. " $\mathrm{P}<0.05$ vs. Nthy-ori3-1 cells; ${ }^{~} \mathrm{P}<0.05$ vs. the si-LRRK2-2 and si-LRRK2-3 groups. The measurement data were expressed as the mean \pm standard deviation and data among multiple groups were analyzed using one-way analysis of variance. LRRK2, leucine-rich repeat kinase 2; si, small interfering.

with TC were thyroglobulin (TG), ret proto-oncogene (RET), tumor protein 53 (TP53) and LRRK2, among which TG, RET, and TP53 were known genes associated with TC, but the effect of LRRK on TC remained unclear.

The SW579 cell line has the highest LRRK2 expression, while the IHH-4 cell line has the lowest LRRK2 expression, and si-LRRK2-1 exhibits the best interference effect on LRRK2 expression. According to the results of cell screening by RT-qPCR and western blot analysis (Fig. 2A-C), compared with normal thyroid cell line Nthy-ori3-1, the four human TC cell lines all exhibited a significant reduction in LRRK2 mRNA and protein expression levels $(\mathrm{P}<0.05)$. However, the SW579 cell line revealed the highest LRRK2 mRNA and protein expression levels, and the IHH-4 cell line exhibited the lowest. Therefore, the SW579 and IHH-4 cell lines were selected for subsequent experiments.

RT-qPCR and western blot analysis were conducted to detect the LRRK2 mRNA and protein expression levels in three si-LRRK2-transfected cells. The results (Fig. 2D-F) demonstrated that LRRK2 mRNA and protein expression among the three groups were ranked as follows (highest to lowest): si-LRRK2-3, si-LRRK2-2 group and then si-LRRK2-1 group $(\mathrm{P}<0.05$, compared with the si-LRKK2-2 and si-LRRK2-3 groups). These data indicate that the si-LRRK2-1 group had the best interference effect on LRRK2 expression in TC cell lines. Therefore, si-LRRK2-1 was selected for further experiments.

Repression of LRRK2 inhibits the activation of the JNK signaling pathway in TC cells. To determine whether LRRK2 affects JNK, MMP-9, Cyclin A, Cyclin D1, Bcl-2, CDK4, Bax and p16 mRNA expression, RT-qPCR was conducted following transfection, the results of which are depicted in Fig. 3. The blank and NC groups demonstrated no significant differences in LRRK2, JNK, MMP-9, Cyclin A, Cyclin D1, Bcl-2, CDK4, Bax or p16 mRNA expression (all P>0.05). Compared with the blank and NC groups, the pcDNA-LRRK2 group exhibited significantly upregulated mRNA expression levels of LRRK2, JNK, MMP-9, Cyclin A, Cyclin D1, Bcl-2 and CDK4, but significantly downregulated mRNA expression levels of Bax and p16, which was opposite to the tendencies of the si-LRRK2, SP600125 and si-LRRK2 + SP600125 groups $(\mathrm{P}<0.05)$. Compared with the expression in the si-LRRK2 group, the mRNA expression levels of LRRK2, JNK, MMP-9, Cyclin A, Cyclin D1, Bcl-2 and CDK4 were significantly decreased, while those of Bax and p16 were significantly increased in the si-LRRK2 + SP600125 group $(\mathrm{P}<0.05)$. The results in the SW579 and IHH-4 cell lines demonstrated a consistent tendency. These results provide evidence that LRRK2 silencing could inhibit the activation of the JNK signaling pathway, which in turn, results in increased mRNA expression of Bax and p16 and reduced expression of MMP-9, Cyclin A, Cyclin D1, Bcl-2 and CDK4.

To investigate whether LRRK2 could alter the extent of p-JNK, as well as the protein expression of JNK, MMP-9, Cyclin A, Cyclin D1, Bcl-2, CDK4, Bax and p16 following transfection, western blot analysis was conducted. As depicted in Fig. 4, there was no significant difference observed regarding the protein expression levels of LRRK2, MMP-9, Cyclin A, Cyclin D1, Bcl-2, CDK4, Bax and p16 following cell transfection among the blank and NC groups $(\mathrm{P}>0.05)$. Compared with the expression levels in the blank and $\mathrm{NC}$ groups, the protein expression levels of LRRK2, MMP-9, Cyclin A, Cyclin D1, Bcl-2, and CDK4 as well as the ratio of $\mathrm{p}-\mathrm{JNK} / \mathrm{JNK}$ were elevated, while those of Bax and p16 
A

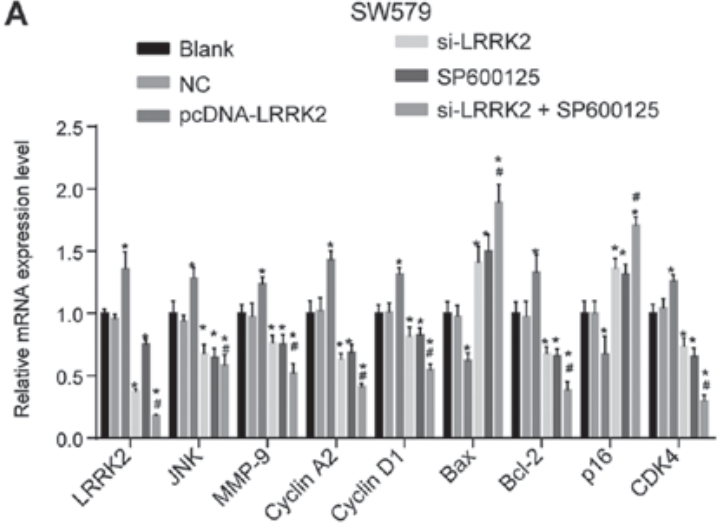

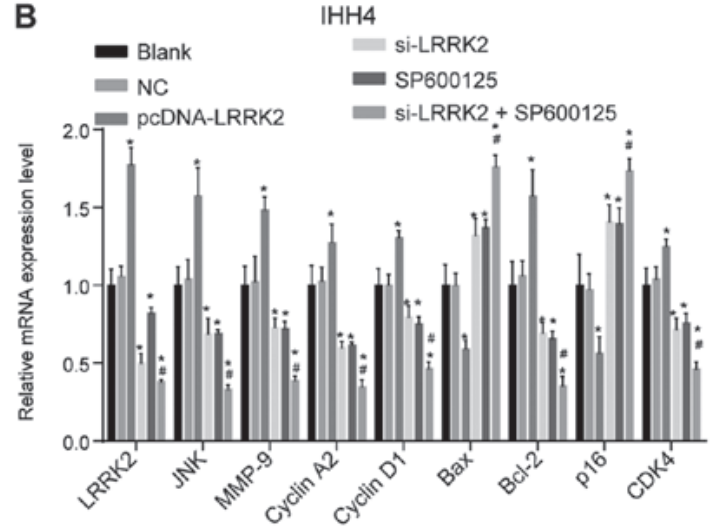

Figure 3. Reverse transcription-quantitative polymerase chain reaction demonstrated that, via the inactivation of the JNK signaling pathway, downregulation of LRRK2 elevates the mRNA expression levels of Bax and p16 and declines those of MMP-9, Cyclin A, Cyclin D1, Bcl-2 and CDK4 in thyroid cancer cells. (A) SW579 cell line. (B) IHH-4 cell line. The experiment was independently repeated in triplicate. ${ }^{*} \mathrm{P}<0.05$ vs. the blank and NC groups; ${ }^{\text {P }}<0.05$ vs. the si-LRRK2 group. The measurement data were expressed as the mean \pm standard deviation and data among multiple groups were analyzed using one-way analysis of variance; LRRK2, leucine-rich repeat kinase 2; JNK, c-Jun N-terminal kinase; NC, negative control; si, small interfering; MMP-9, matrix metalloproteinase-9; CDK4, cyclin-dependent kinase 4; Bcl-2, B-cell lymphoma-2; Bax, Bcl-2-associated X.

A

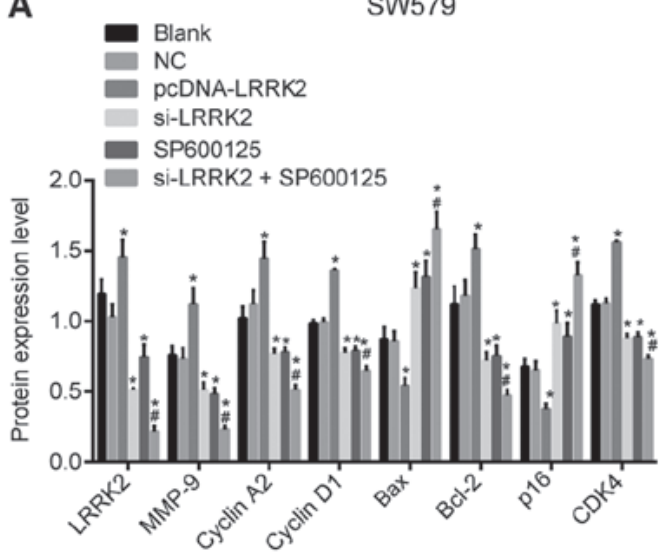

B

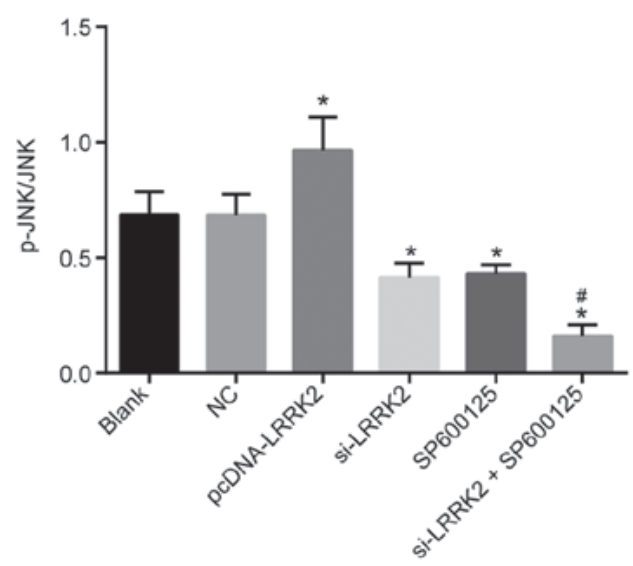

E

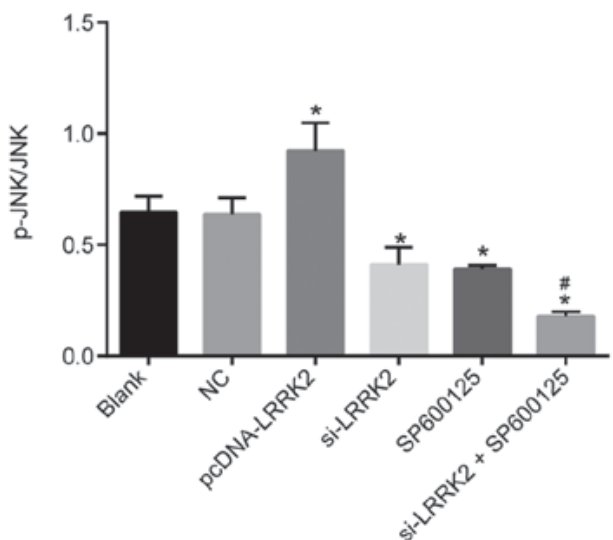

$\mathrm{IHH}-4$
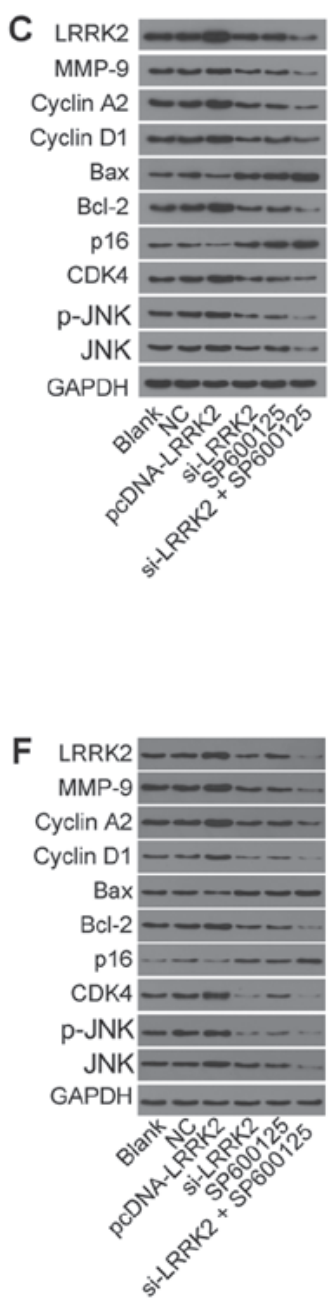

Figure 4. According to western blot analysis, silencing of LRRK2 increases the protein expression levels of Bax and p16, and declines those of MMP-9, Cyclin A, Cyclin D1, Bcl-2 and CDK4 by repressing the JNK signaling pathway in thyroid cancer cells. (A) Protein expression of associated proteins in the SW579 cell line. (B) The ratio of p-JNK/JNK in the SW579 cell line. (C) Protein bands of associated proteins in the SW579 cell line. (D) Protein expression of associated proteins in the IHH-4 cell line. (E) The ratio of p-JNK/JNK in the IHH-4 cell line. (F) Protein bands of associated proteins in the IHH-4 cell line. The experiment was independently repeated in triplicate. ${ }^{*} \mathrm{P}<0.05$ vs. the blank and $\mathrm{NC}$ groups. " $\mathrm{P}<0.05$ vs. the si-LRRK2 group. The measurement data were expressed as the mean \pm standard deviation and data among multiple groups were analyzed using one-way analysis of variance. LRRK2, leucine-rich repeat kinase 2; p-JNK, phospho-c-Jun N-terminal kinase; NC, negative control; si, small interfering; MMP-9, matrix metalloproteinase-9; CDK4, cyclin-dependent kinase 4; Bcl-2, B-cell lymphoma-2; Bax, Bcl-2-associated X. 

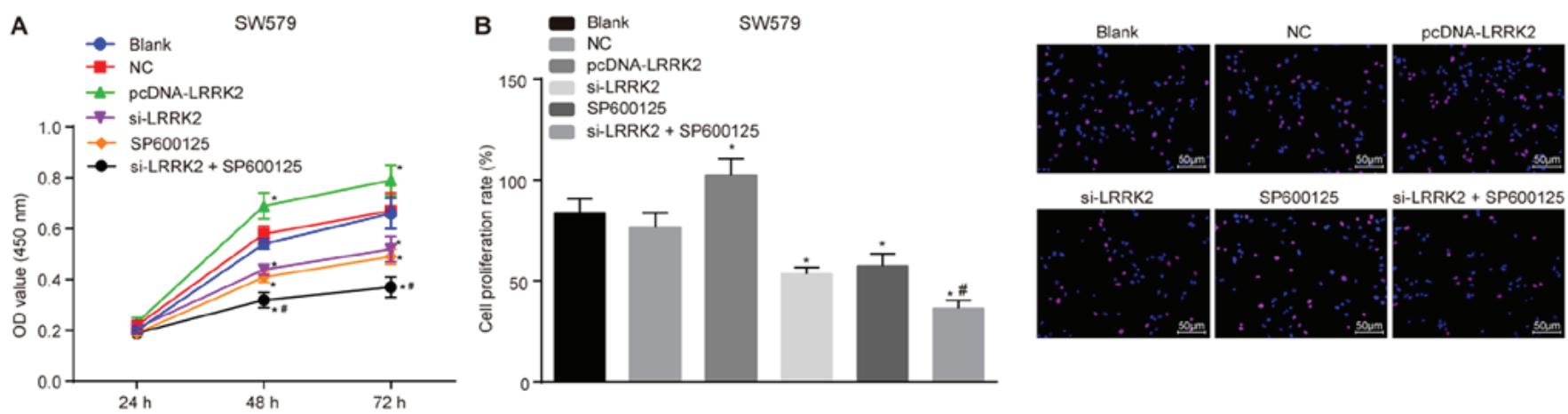

si-LRRK2

SP600125

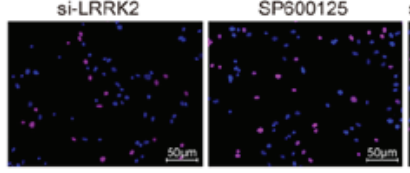

Si-LRRK2 + SP600125
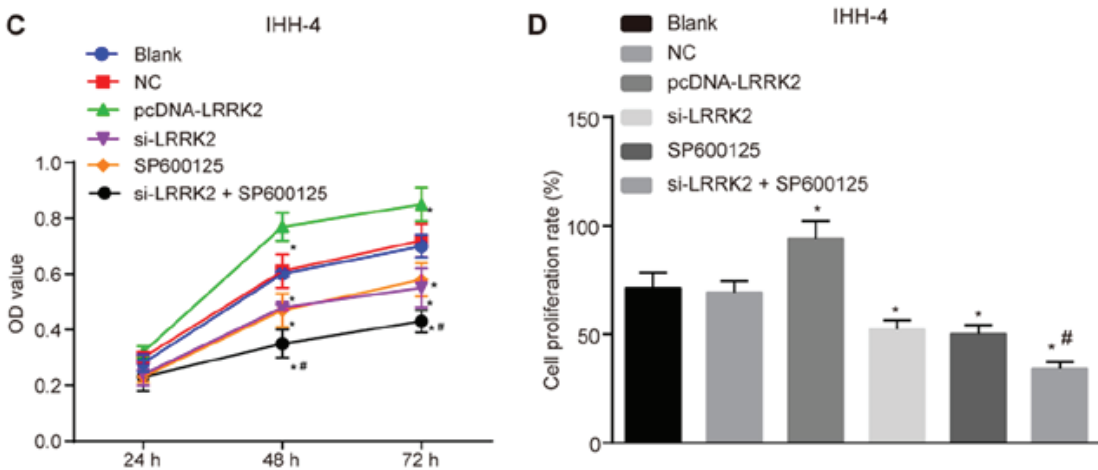

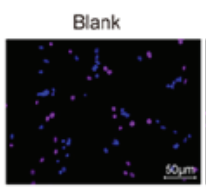

Si-LRRK2

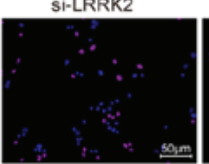

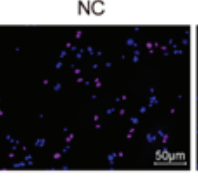

SP600125

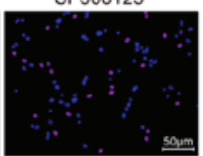

pCDNA-LRRK2

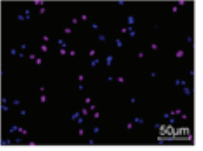

Si-LRRK2 + SP600125

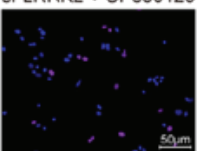

Figure 5. LRRK2 silencing suppresses cell proliferation through inactivating the c-Jun N-terminal kinase signaling pathway in thyroid cancer, as determined by Rhodamine B staining and the EdU assay. (A) OD value of the SW579 cell line in each group. (B) Fluorescence observation and cell proliferation rate of the SW579 cell line in each group (x200). (C) OD value of the IHH-4 cell line in each group. (D) Fluorescence observation and cell proliferation rate of the IHH-4 cell line in each group (x200). The experiment was independently repeated in triplicate. " P<0.05 vs. the blank and NC groups. " $\mathrm{P}<0.05$, vs. the si-LRRK2 group. The measurement data were expressed as the mean \pm standard deviation and data among multiple groups were analyzed using one-way analysis of variance. Cell viability at different time points was analyzed using repeated measurement analysis of variance. LRRK2, leucine-rich repeat kinase 2; EdU, 5-ethynyl-2erdeoxyuridine; OD, optical value; NC, negative control; si, small interfering.

were reduced in the pcDNA-LRRK2 group $(\mathrm{P}<0.05)$. The si-LRRK2, SP600125 and si-LRRK2 + SP600125 groups implicated opposite tendencies with the pcDNA-LRRK2 group $(\mathrm{P}<0.05)$. Compared with the si-LRRK2 group, the si-LRRK2 + SP600125 group exhibited significantly decreased protein expression of LRRK2, MMP-9, Cyclin A, Cyclin D1, $\mathrm{Bcl}-2$, and CDK4 as well as the ratio of $\mathrm{p}-\mathrm{JNK} / \mathrm{JNK}$, but significantly increased expression of Bax and p16 $(\mathrm{P}<0.05)$. The results in the SW579 and IHH-4 cell lines exhibited a consistent tendency. The results indicate that downregulated LRRK2 may elevate the protein expression levels of Bax and p16, and reduce MMP-9, Cyclin A, Cyclin D1, Bcl-2 and CDK4 protein expression levels as well as the ratio of $\mathrm{p}-\mathrm{JNK} / \mathrm{JNK}$ by inhibiting the JNK signaling pathway.

Downregulated LRRK2 inhibits TC cell proliferation. Subsequently, SRB staining was performed to detect cell viability. The results (Fig. 5A) demonstrated that SW579 cells had the same tendency as the IHH-4 cell line. There was no significant difference in TC cell viability between the blank and NC groups $(\mathrm{P}>0.05)$. Compared with the blank and NC groups, the pcDNA-LRRK2 group exhibited significantly enhanced cell viability, while the si-LRRK2, SP600125, and si-LRRK2 + SP600125 groups exhibited significantly restrained cell viability $(\mathrm{P}<0.05)$. The si-LRRK2 + SP600125 group exhibited suppressed cell viability, compared with the si-LRRK2 group $(\mathrm{P}<0.05)$. These data indicate that downregulated LRRK2 could inhibit cell viability in TC through suppressing the activation of the JNK signaling pathway.

The EdU assay was employed to determine cell proliferation. The results (Fig. 5B-D) demonstrated that the SW579 cell line had the same tendency as the IHH-4 cell line. There was no significant difference in TC cell proliferation between the blank and NC groups $(\mathrm{P}>0.05)$. The pcDNA-LRRK2 group exhibited significantly increased cell proliferation, and the si-LRRK2, SP600125 and si-LRRK2 + SP600125 groups exhibited significantly reduced cell proliferation, compared with the blank and NC groups $(\mathrm{P}<0.05)$. Cell proliferation was significantly reduced in the si-LRRK2 + SP600125 group, compared with the si-LRRK2 group $(\mathrm{P}<0.05)$. Therefore, reduced LRRK2 expression represses cell proliferation in TC cells via inactivating with the JNK signaling pathway.

Repression of LRRK2 inhibits TC cell migration. Subsequently, a scratch test was conducted to determine cell migration. As depicted in Fig. 6, the SW579 and IHH-4 cell lines had the same tendency. The blank and NC groups exhibited no significant difference in TC cell migration $(\mathrm{P}>0.05)$. The pcDNA-LRRK2 group exhibited significantly enhanced migration ability, while the si-LRRK2, SP600125 and si-LRRK2 + SP600125 groups exhibited significantly weakened migration ability, compared with the blank and NC groups $(\mathrm{P}<0.05)$. The si-LRRK2 + SP600125 group exhibited significantly reduced migration ability, compared 


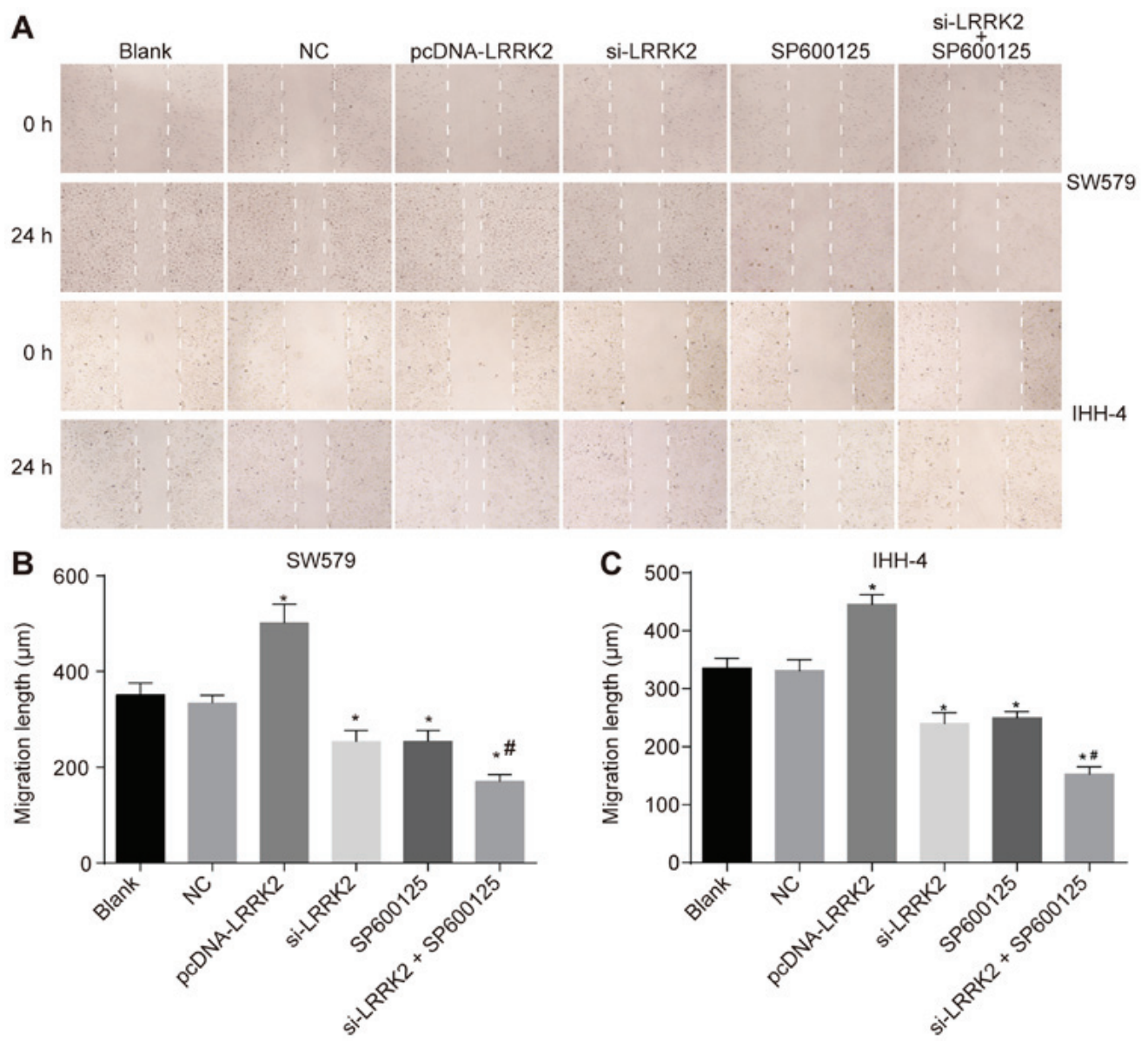

Figure 6. Low expression of LRRK2 inhibits TC cell migration via inactivation of the c-Jun N-terminal kinase signaling pathway. (A) SW579 and IHH-4 cell migration in each group (x100). (B) Migration distance of the SW579 cell line in each group. (C) Migration distance of the IHH-4 cell line in each group. The experiment was independently repeated in triplicate. ${ }^{*} \mathrm{P}<0.05$ vs. the blank and NC groups; ${ }^{\mathrm{P}}<0.05$ vs. the si-LRRK2 group. The measurement data were expressed as the mean \pm standard deviation and data among multiple groups were analyzed using one-way analysis of variance. LRRK2, leucine-rich repeat kinase 2; TC, thyroid cancer; NC, negative control; si, small interfering.

with the si-LRRK2 group $(\mathrm{P}<0.05)$. These data provide evidence that low expression of LRRK2 could suppress JNK signaling pathway activation, thus inhibiting cell migration in TC cells.

Downregulation of LRRK2 promotes cell cycle arrest and apoptosis via inactivation of the JNK signaling pathway in TC cells. Subsequently, the effects of LRRK2 and the JNK signaling pathway on the cell cycle distribution of TC cells was investigated using flow cytometry. The results (Fig. 7) demonstrated that the SW579 and IHH-4 cell lines had the same tendency. The blank and NC groups revealed no significant difference in cell cycle arrest or apoptosis $(\mathrm{P}>0.05)$. Compared with the blank and NC groups, the pcDNA-LRRK2 group had significantly fewer cells arrested at the G0/G1 phase but significantly increased cells at the $\mathrm{S}$ phase, indicating a low apoptosis rate of TC cells; however, the si-LRRK2, SP600125 and si-LRRK2 + SP600125 groups exhibited significantly increased cells arrested at the G0/G1 phase but significantly fewer cells at the $\mathrm{S}$ phase, exhibiting increased apoptosis rates with the cell cycle arrest of TC cells $(\mathrm{P}<0.05)$. Collectively, decreased LRRK2 expression may enhance cell cycle arrest and apoptosis in TC cells by inhibiting the activation of the JNK signaling pathway.
Downregulated LRRK2 contributes to light blue fluorescence in TC cells with complete cell membrane and plentiful cytoplasm, and promotes positive staining signal. The morphology of cell apoptosis was observed under a fluorescence microscope (Fig. 8A). It was observed that the SW579 cell line had the same tendency as the IHH-4 cell line. Following staining with the DNA fluorescent dye Hoechst 33258, all groups exhibited cells with agglutinated and marginalized nuclear chromatins, as well as partial cells with apoptotic bodies, nuclear concentration and fragmentation and nuclear membrane that disappeared or bulged in the shape of vesicles. Apoptotic bodies were marginally blurry and crumpled and were notably smaller, compared with the peripheral normal nucleus with bright blue fluorescence. The si-LRRK2, SP600125 and si-LRRK2 + SP600125 groups had more complete cell membranes, plentiful cytoplasm, and round or nearly round nuclei with a uniform size and light blue fluorescence; compared with the fluorescence in the blank group, the bright blue fluorescence was significantly increased in the aforementioned three groups.

Results of TUNEL staining were observed under the fluorescence microscope (Fig. 8B-D). The SW579 cell line had the same trend as the IHH-4 cell line. In comparison with the blank and NC groups, the pCDNA-LRRK2 group 

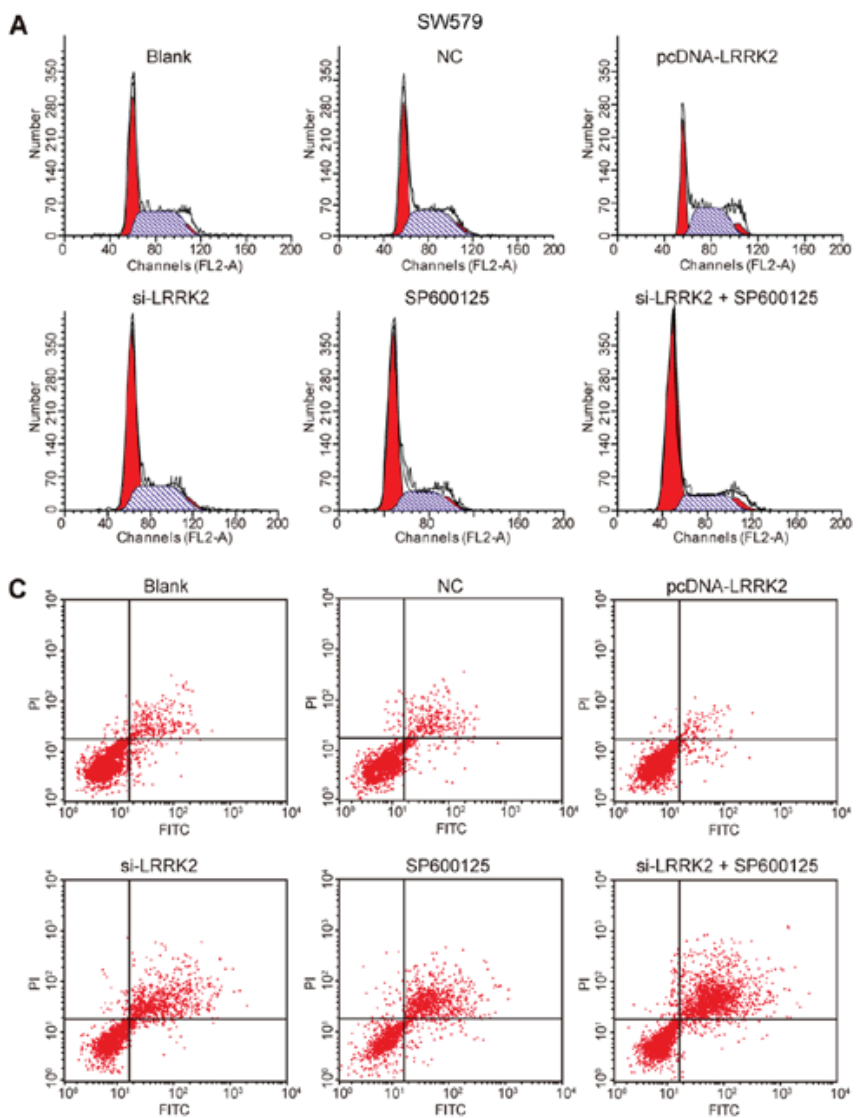

E
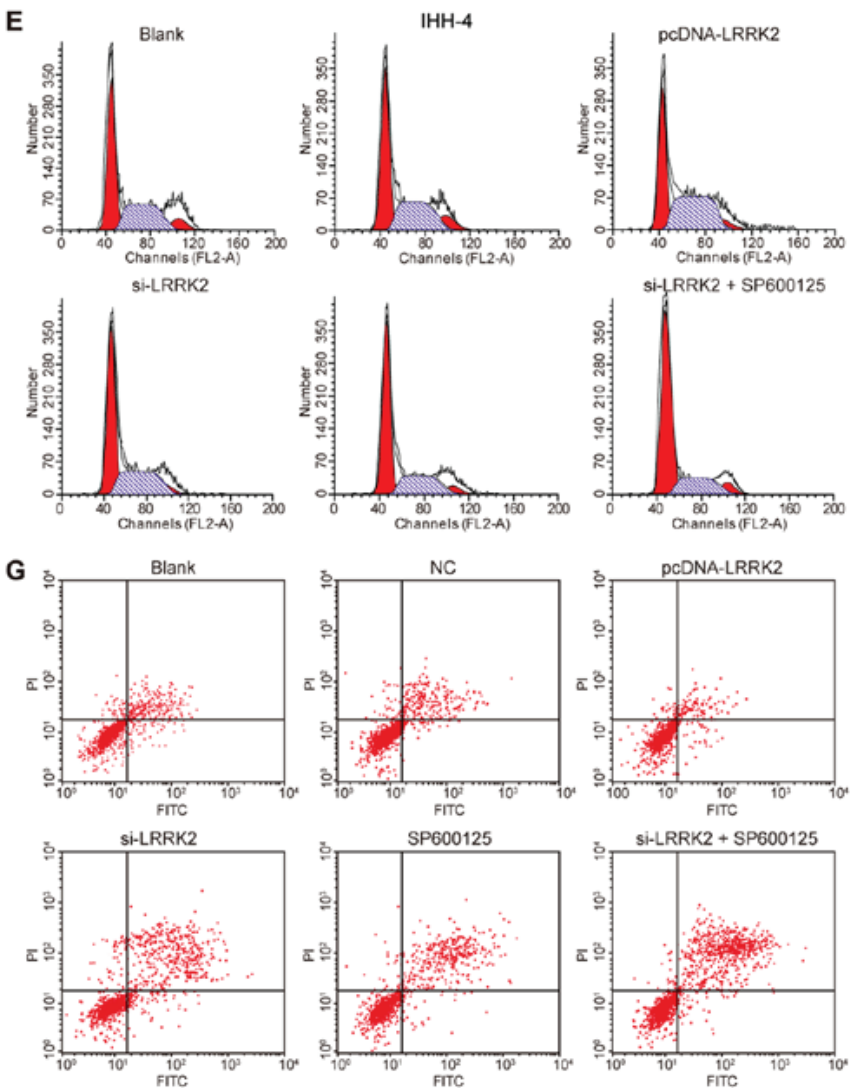
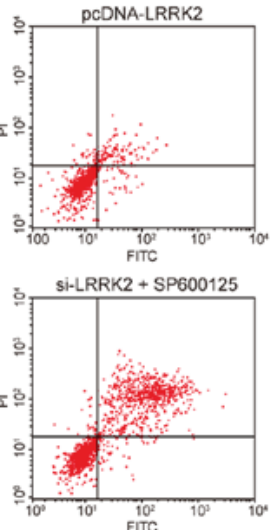

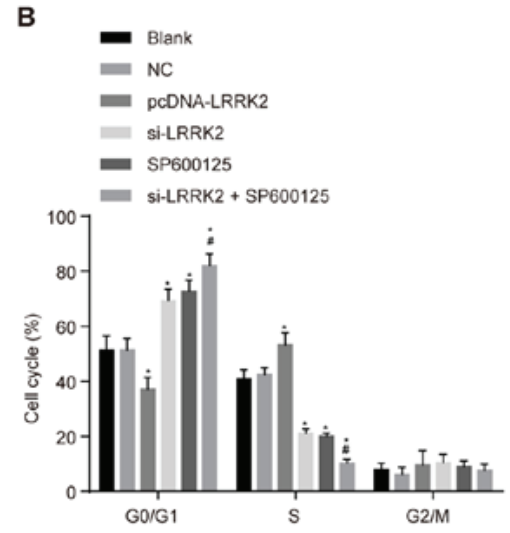

D

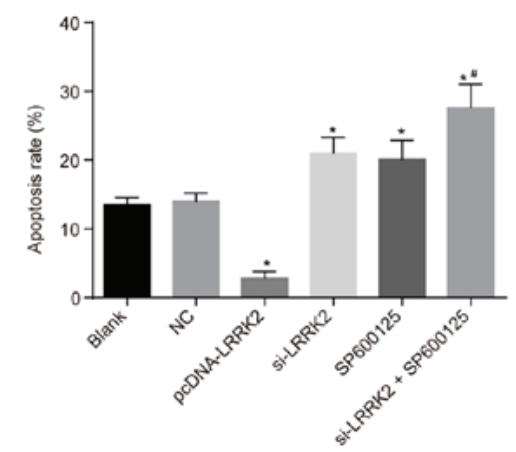

$\mathbf{F}$

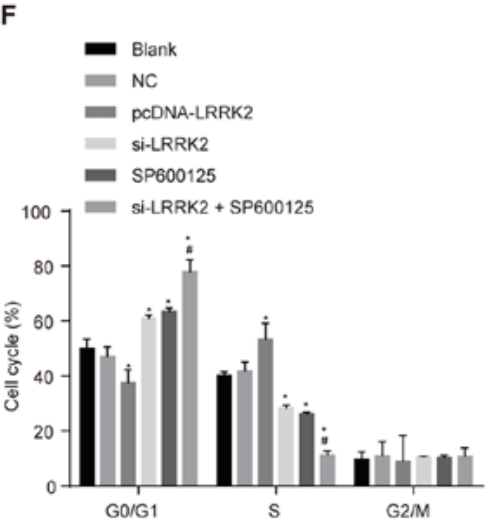

H

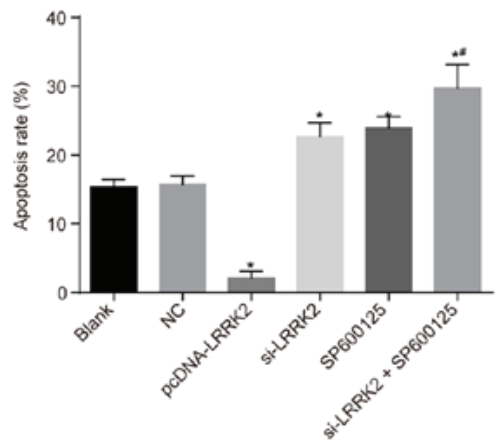

Figure 7. Flow cytometry demonstrated that low expression of LRRK2 inhibits the activation of the c-Jun N-terminal kinase signaling pathway, thus promoting cell cycle arrest and apoptosis in thyroid cancer cells. (A) Cell cycle distribution of the SW579 cell line in each group. (B) Histogram of cell cycle distribution of the SW579 cell line in each group. (C) Cell apoptosis rate of the SW579 cell line in each group. (D) Histogram of cell apoptosis rate of the SW579 cell line in each group. (E) Cell cycle distribution of the IHH-4 cell line in each group. (F) Histogram of cell cycle distribution of the IHH-4 cell line in each group. (G) Cell apoptosis rate of the IHH-4 cell line in each group. (H) Histogram of cell apoptosis rate of the IHH-4 cell line in each group. The experiment was independently repeated in triplicate. "P $<0.05$ vs. the blank and $\mathrm{NC}$ groups; ${ }^{*} \mathrm{P}<0.05$, vs. the si-LRRK2 group. The measurement data were expressed as the mean \pm standard deviation and data among multiple groups were analyzed using one-way analysis of variance. LRRK2, leucine-rich repeat kinase 2; si, small interfering; NC, negative control. 


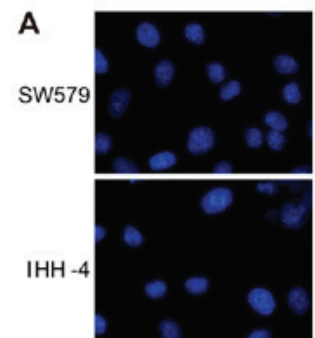

Blank
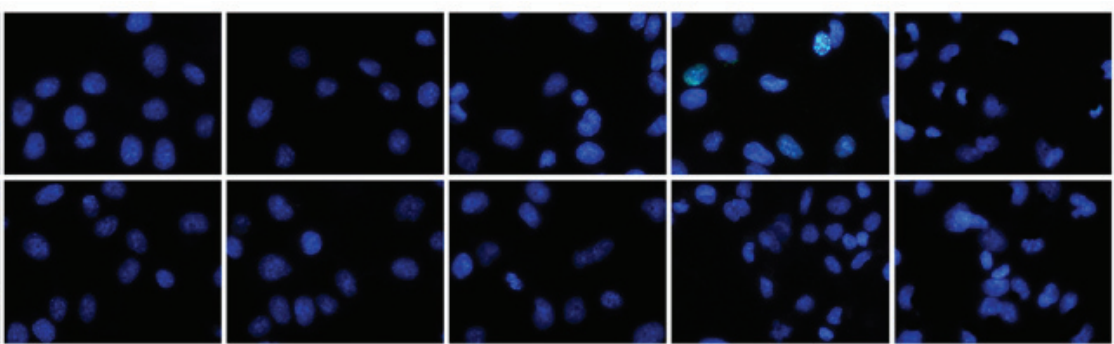

SP600125
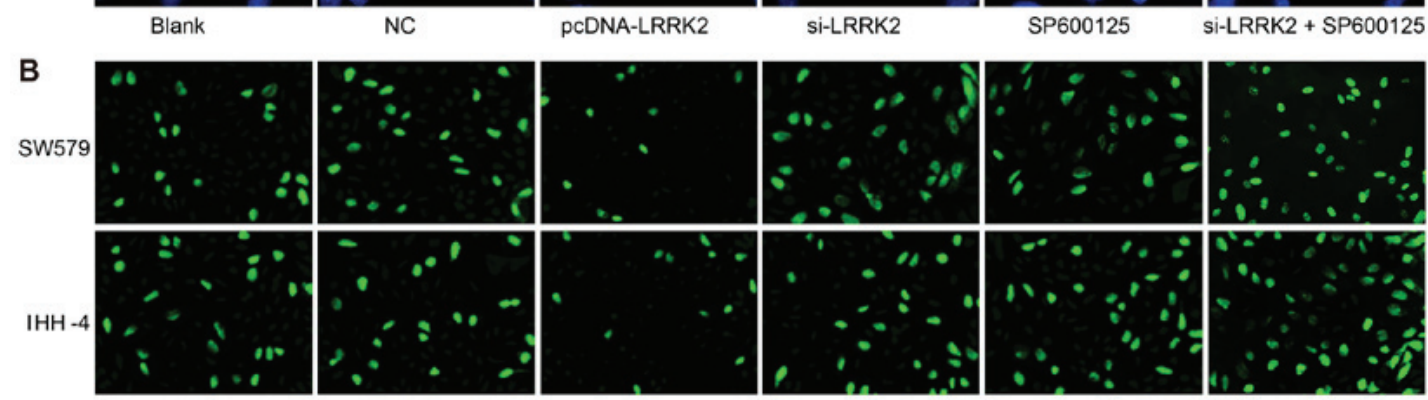

NC pcDNA-LRRK2 Si-LRRK2

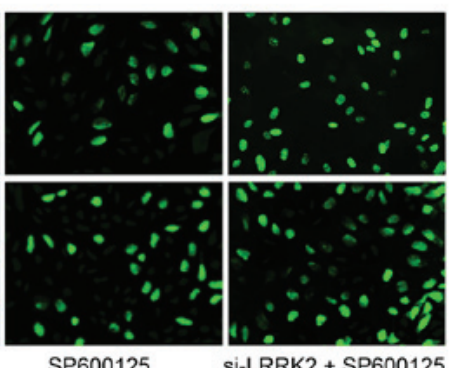

NC

C

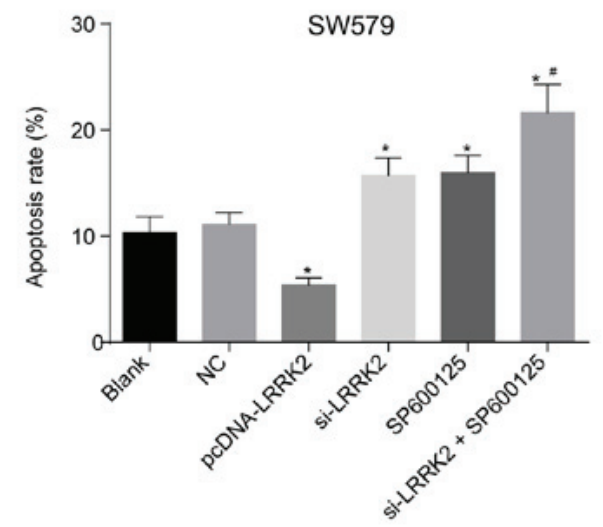

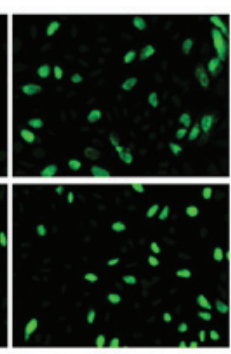

si-LRRK2
SP600125

D

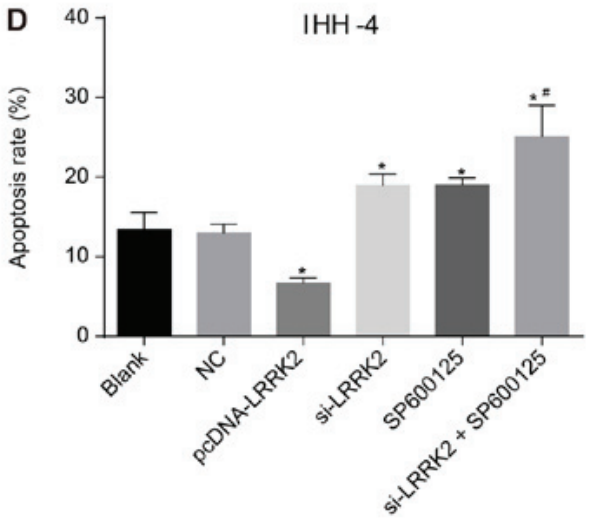

Figure 8. Thyroid cancer cells with silenced LRRK2 exhibit increased complete cell membranes, plentiful cytoplasm, and round nuclei with a uniform size, light blue fluorescence, and enhanced positive staining signals under a fluorescence microscope. (A) Morphology of cells in each group following Hoechst 33258 staining (x400). (B) Morphology of cells observed following a terminal deoxynucleotidyl transferase-mediated dUTP-biotin nick end labeling assay (x400). (C) Cell apoptosis in the SW579 cell line. (D) Cell apoptosis in the IHH-4 cell line. The measurement data were expressed as the mean \pm standard deviation and data among multiple groups were analyzed using one-way analysis of variance. The experiment was independently repeated in triplicate; LRRK2, leucine-rich repeat kinase; NC, negative control; si, small interfering.

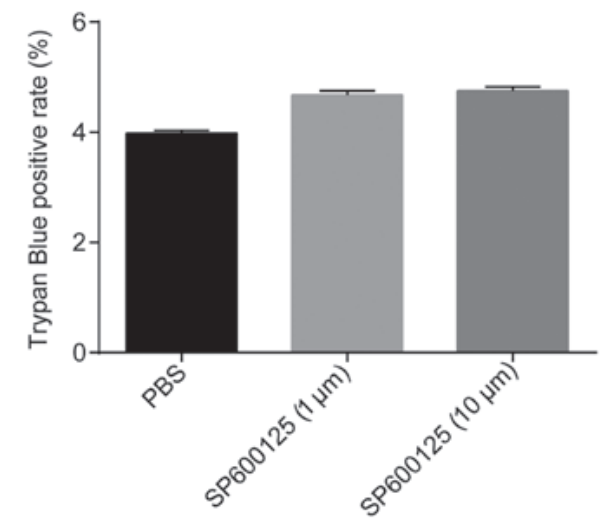

Figure 9 . Detection of cytotoxicity of sp600125 by trypan blue staining (x400).

had weakened positive staining signal, while the si-LRRK2, SP600125, si-LRRK2 + SP600125 groups exhibited promoted positive staining signal with increased apoptotic cells. Therefore, the conclusion can be drawn that cells exhibit light blue fluorescence with the complete cell membrane and plentiful cytoplasm, and promote positive staining signal owing to downregulation of LRRK2.

SP600125 exhibits no cytotoxicity. The results demonstrated that after $24 \mathrm{~h}$ of treatment with SP600125 (1 and $10 \mu \mathrm{M})$, the positive rate of SW579 cells with trypan blue staining was $<5 \%$, indicating that SP600125 is not cytotoxic to these cells (Fig. 9).

\section{Discussion}

TC is a type of cancer accounting for $\sim 1-2 \%$ of all human cancer types, while papillary and follicular TC are the two most common histological varieties (27). Among various treatment options, multi-kinase inhibitors are the most promising (28). In the present study, the effects of LRRK2 on TC cells were investigated. The results revealed that LRRK2 downregulation can enhance cell cycle arrest and apoptosis by inhibiting JNK signaling pathway activation in TC cells. 


\section{TC}
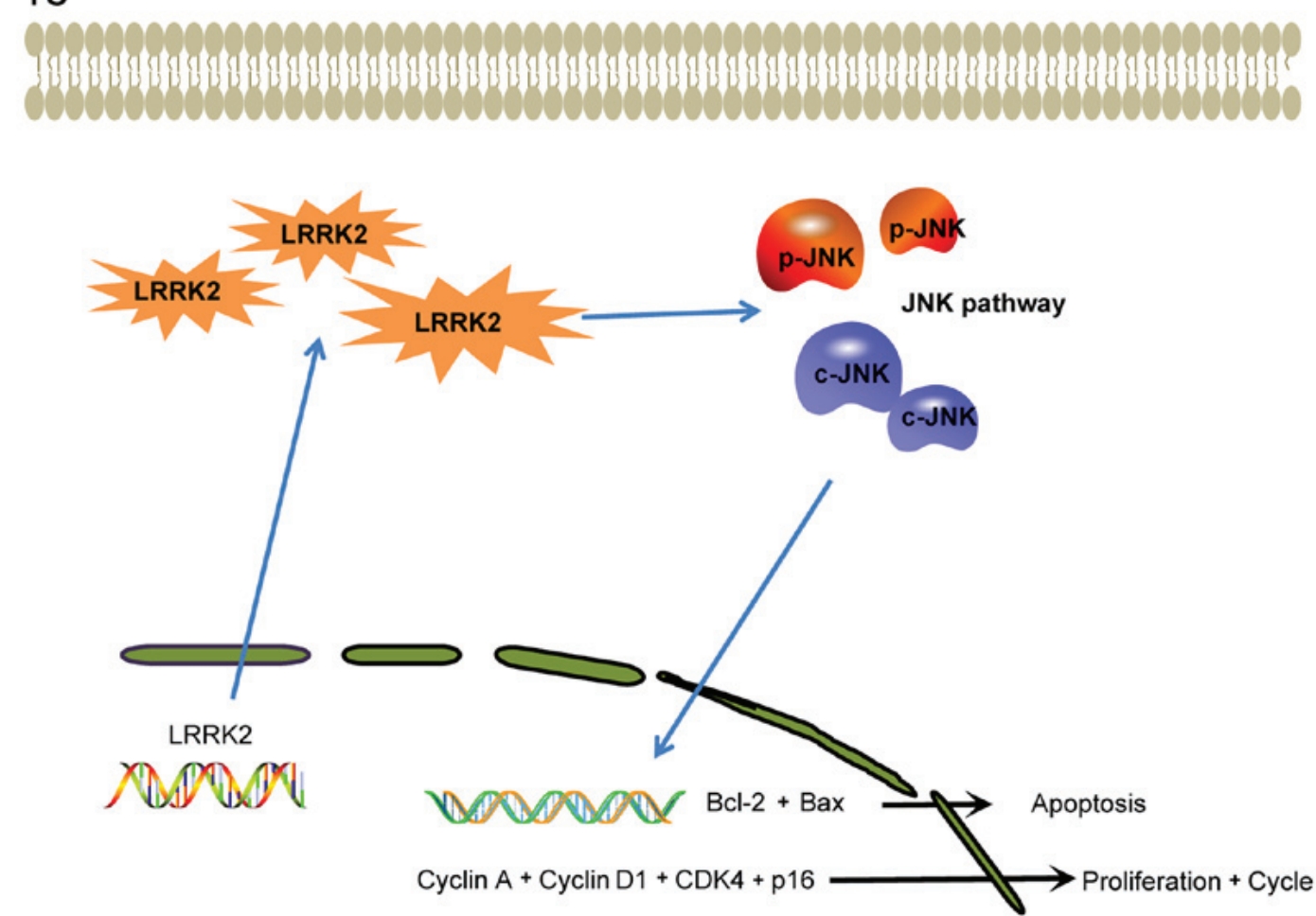

Figure 10. Model of the molecular mechanisms involved in LRRK2 gene silencing in proliferation, migration, and apoptosis in TC cells. LRRK2 is upregulated with inhibition of the JNK pathway in TC cells. Downregulated LRRK2 exerts its inactivation effect on the JNK signaling pathway, successively promoting cell growth and enhancing apoptosis and cell cycle arrest in TC cells. LRRK2, leucine-rich repeat kinase 2; TC, thyroid cancer; JNK, p-JNK, phospho-c-Jun N-terminal kinase; c-JNK, c-Jun N-terminal kinase; MMP-9, matrix metalloproteinase-9; CDK4, cyclin-dependent kinase 4; Bcl-2, B-cell lymphoma-2; Bax, Bcl-2-associated X.

Firstly, it was determined that the LRRK2 gene was expressed at a high level and phosphorylated the JNK signaling pathway in TC cells. LRRK2 expression was reported to be ubiquitous, and its expression levels were different among organs and tissues (29). A previous study provided evidence that the expression level of the LRRK2 gene was increased in the kidney, lung, and spleen, compared with in the brain (29). Similarly, when reacted with the mesenchymal-epithelial transition (MET) signaling pathway, the expression of the LRRK2 gene was previously demonstrated to be increased in papillary TC (19). Furthermore, targeting LRRK2 may be regarded as an appealing pharmacologic approach to complement MET inhibitors in patients with specific papillary tumors (19). The JNK signaling pathway is involved in cellular processes, including proliferation, differentiation and apoptosis, and is implicated in a number of diseases, including cancer, and neurological and immunological/inflammatory conditions (30). Activation of the JNK signaling pathway is involved in cell apoptosis due to numerous stimuli in cancer types, including breast and ovarian cancer $(31,32)$. LRRK2 has been previously demonstrated to be able to act as a functional kinase mediating the autophosphorylation or phosphorylation of generic kinase substrates (33). The JNK signaling pathway was reported to be highly phosphorylated in human cytomegalovirus in a previous study (34). Additionally, evidence has demonstrated that JNK phosphorylation facilitates apoptosis in a number of ovarian cancer cells (35). Published reports demonstrated that the proliferation, growth and invasiveness of TC cells could be inhibited or elevated through phosphorylation of different signaling pathways or genes, including the Akt signaling pathway or the CD44 gene $(36,37)$.

Another observation of the present study was that repression of LRRK 2 enhanced cell cycle arrest and apoptosis and suppressed cell migration and proliferation in TC cells, as indicated by the reduced expression of MMP-9, Cyclin A, Cyclin D1,Bcl-2 and CDK4, along with the increased expression of Bax and p16. In breast cancer, the protein expression levels of MMP-9 and Cyclin D1 were demonstrated to be decreased through downregulated metastasis-associated protein 1 via the RNAi pathway (38). The same tendency of Cyclin D1 and Bcl-2 was determined in HepG2 and Hep3B cells through Notch1, which elevated the expression of Bax (39). Cyclin A and p16 are genes that regulate the cell cycle, and their upregulation has been respectively identified in colorectal and breast cancer $(40,41)$. Cyclin D1 expression was reported to be positively associated with activation of the JNK pathway (42). CDK4 serves a pivotal role in G1-phase progression in oral squamous cell carcinoma via Cyclin D (43). LRRK2 has been detected in most immune cells, including T cells, B cells and various subtypes of monocytes (44). Reduced mutant (G2019S) LRRK2 was once reported to inhibit the mitogen-activated protein kinase 4-JNK-c-Jun pathway in PD $(45,46)$. Repression of LRRK2 was demonstrated to allay microglial inflammatory responses $(47,48)$. Furthermore, LRRK2 downregulation could result in a spectrum of developmental deviations combined with a neuronal loss (49). A recent study elucidated that the downregulation of tectonic 1 promoted cell cycle arrest and apoptosis, thus inhibiting cell 
proliferation in TC cells (50), an observation that is consistent with the data of the present study.

Accordingly, the present study illuminates potential molecular mechanisms by which LRRK2 silencing-forced inactivation of the JNK signaling pathway triggers cell cycle arrest and apoptosis in TC cells (Fig. 10). However, considering the inevitable limitations, including limited sample size, more detailed and large-scale studies are required in the future. Therefore, the present study provides a key target for the treatments of TC through the study of JNK inhibitors. However, further studies are required to elucidate the specific mechanisms by which JNK inhibitors ameliorate TC, and a larger sample size should be employed.

\section{Acknowledgements}

The authors would like to acknowledge the helpful comments on the present paper received from our reviewers.

\section{Funding}

The present study was supported by Scientific Research Program of Zhejiang Medical Association (grant no. 2015ZYC-A25).

\section{Availability of data and materials}

All of data and materials during the study are available from the corresponding author on reasonable request.

\section{Authors' contributions}

WJW, XHG and XC designed the study. XJC and QZ collated the data, and designed and developed the database. WJW and XHG conducted the data analyses and produced the initial draft of the manuscript. WJW, and XC wrote the main manuscript text. QZ prepared the figures. ZCJ revised it critically for important intellectual content. All authors have read and approved the final submitted manuscript.

\section{Ethics approval and consent to participate}

Not applicable

\section{Patient consent for publication}

Not applicable.

\section{Competing interests}

The authors declare that they have no competing interests.

\section{References}

1. Lun Y, Wu X, Xia Q, Han Y, Zhang X, Liu Z, Wang F, Duan Z, Xin $\mathrm{S}$ and Zhang J: Hashimoto's thyroiditis as a risk factor of papillary thyroid cancer may improve cancer prognosis. Otolaryngol Head Neck Surg 148: 396-402, 2013.

2. Nikiforov YE and Nikiforova MN: Molecular genetics and diagnosis of thyroid cancer. Nat Rev Endocrinol 7: 569-580, 2011.

3. Xing M: Molecular pathogenesis and mechanisms of thyroid cancer. Nat Rev Cancer 13: 184-199, 2013.
4. Nikiforov YE: Is ionizing radiation responsible for the increasing incidence of thyroid cancer? Cancer 116: 1626-1628, 2010.

5. Leux C, Truong T, Petit C, Baron-Dubourdieu D and Guénel P: Family history of malignant and benign thyroid diseases and risk of thyroid cancer: A population-based case-control study in New Caledonia. Cancer Causes Control 23: 745-755, 2012.

6. Brindel P, Doyon F, Bourgain C, Rachédi F, Boissin JL, Sebbag J, Shan L, Bost-Bezeaud F, Petitdidier P, Paoaafaite J, et al: Family history of thyroid cancer and the risk of differentiated thyroid cancer in French polynesia. Thyroid 20: 393-400, 2010.

7. Pellegriti G, Frasca F, Regalbuto C, Squatrito S and Vigneri R: Worldwide increasing incidence of thyroid cancer: Update on epidemiology and risk factors. J Cancer Epidemiol 2013: 965212 , 2013.

8. Chen W, Zheng R, Baade PD, Zhang S, Zeng H, Bray F, Jemal A, $\mathrm{Yu}$ XQ and He J: Cancer statistics in China, 2015. CA Cancer J Clin 66: 115-132, 2016.

9. Davies L and Welch HG: Current thyroid cancer trends in the United States. JAMA Otolaryngol Head Neck Surg 140: 317-322, 2014.

10. Nexø MA, Watt T, Cleal B, Hegedüs L, Bonnema SJ, Rasmussen AK, Feldt-Rasmussen U and Bjorner JB: Exploring the experiences of people with hypo- and hyperthyroidism. Qual Health Res 25: 945-953, 2015.

11. Rowe CW, Bendinelli C and McGrath S: Charting a course through the CEAs: Diagnosis and management of medullary thyroid cancer. Clin Endocrinol (Oxf) 85: 340-343, 2016.

12. Lubitz CC and Sosa JA: The changing landscape of papillary thyroid cancer: Epidemiology, management, and the implications for patients. Cancer 122: 3754-3759, 2016.

13. Al-Humadi H, Zarros A, Al-Saigh R and Liapi C: Genetic basis and gene therapy trials for thyroid cancer. Cancer Genomics Proteomics 7: 31-49, 2010.

14. Nikonova EV, Xiong Y, Tanis KQ, Dawson VL, Vogel RL, Finney EM, Stone DJ, Reynolds IJ, Kern JT and Dawson TM: Transcriptional responses to loss or gain of function of the leucine-rich repeat kinase 2 (LRRK2) gene uncover biological processes modulated by LRRK2 activity. Hum Mol Genet 21: 163-174, 2012.

15. Kubo M, Kamiya Y, Nagashima R, Maekawa T, Eshima K, Azuma S, Ohta E and Obata F: LRRK2 is expressed in B-2 but not in B-1 B cells, and downregulated by cellular activation. J Neuroimmunol 229: 123-128, 2010.

16. Maekawa T, Mori S, Sasaki Y, Miyajima T, Azuma S, Ohta E and Obata F: The I2020T Leucine-rich repeat kinase 2 transgenic mouse exhibits impaired locomotive ability accompanied by dopaminergic neuron abnormalities. Mol Neurodegener 7: 15, 2012.

17. Piccoli G, Condliffe SB, Bauer M, Giesert F, Boldt K, De Astis S, Meixner A, Sarioglu H, Vogt-Weisenhorn DM, Wurst W, et al: LRRK2 controls synaptic vesicle storage and mobilization within the recycling pool. J Neurosci 31: 2225-2237, 2011.

18. Zechel S, Meinhardt A, Unsicker K and von Bohlen Und Halbach O: Expression of leucine-rich-repeat-kinase 2 (LRRK2) during embryonic development. Int J Dev Neurosci 28: 391-399, 2010.

19. Looyenga BD, Furge KA, Dykema KJ, Koeman J, Swiatek PJ, Giordano TJ, West AB, Resau JH, Teh BT and MacKeigan JP: Chromosomal amplification of leucine-rich repeat kinase-2 (LRRK2) is required for oncogenic MET signaling in papillary renal and thyroid carcinomas. Proc Natl Acad Sci USA 108: 1439-1444, 2011.

20. Wang LL, Huang H, Zhang CR, Xia J, Liu SS and Wang XW: Cloning and functional characterization of c-Jun NH2-terminal kinase from the Mediterranean species of the Whitefly Bemisia tabaci complex. Int J Mol Sci 14: 13433-13446, 2013.

21. Xu B, Yang H, Sun M, Chen H, Jiang L, Zheng X, Ding G, Liu Y, Sheng Y, Cui D, et al: 2,3',4,4',5-pentachlorobiphenyl induces inflammatory responses in the thyroid through JNK and Aryl hydrocarbon receptor-mediated pathway. Toxicol Sci 149: 300-311, 2016

22. Shang J, Ding Q, Yuan S, Liu JX, Li F and Zhang H: Network analyses of integrated differentially expressed genes in papillary thyroid carcinoma to identify characteristic genes. Genes (Basel) 10: E45, 2019.

23. Szklarczyk D, Morris JH, Cook H, Kuhn M, Wyder S, Simonovic M, Santos A, Doncheva NT, Roth A, Bork P, et al: The STRING database in 2017: Quality-controlled protein-protein association networks, made broadly accessible. Nucleic Acids Res 45 (D1): D362-D368, 2017. 
24. Piñero J, Bravo À, Queralt-Rosinach N, Gutiérrez-Sacristán A, Deu-Pons J, Centeno E, García-García J, Sanz F and Furlong LI: DisGeNET: A comprehensive platform integrating information on human disease-associated genes and variants. Nucleic Acids Res 45 (D1): D833-D839, 2017.

25. Piñero J, Queralt-Rosinach N, Bravo À, Deu-Pons J, Bauer-Mehren A, Baron M, Sanz F and Furlong LI: DisGeNET: A discovery platform for the dynamical exploration of human diseases and their genes. Database (Oxford) 2015: bav028, 2015.

26. Livak KJ and Schmittgen TD: Analysis of relative gene expression data using real-time quantitative PCR and the $2(-\Delta \Delta \mathrm{C}(\mathrm{T}))$ Method. Methods 25: 402-408, 2001.

27. Santos LS, Branco SC, Silva SN, Azevedo AP, Gil OM, Manita I, Ferreira TC, Limbert E, Rueff J and Gaspar JF: Polymorphisms in base excision repair genes and thyroid cancer risk. Oncol Rep 28: 1859-1868, 2012.

28. Stjepanovic N and Capdevila J: Multikinase inhibitors in the treatment of thyroid cancer: Specific role of lenvatinib. Biologics 8: 129-139, 2014.

29. Maekawa T, Kubo M, Yokoyama I, Ohta E and Obata F: Age-dependent and cell-population-restricted LRRK2 expression in normal mouse spleen. Biochem Biophys Res Commun 392: 431-435, 2010.

30. Sabapathy K: Role of the JNK pathway in human diseases. Prog Mol Biol Transl Sci 106: 145-169, 2012

31. Dou J, Li X, Cai Y, Chen H, Zhu S, Wang Q, Zou X, Mei Y, Yang Q, $\mathrm{Li} \mathrm{W}$, et al: Human cytomegalovirus induces caspase-dependent apoptosis of megakaryocytic CHRF-288-11 cells by activating the JNK pathway. Int J Hematol 91: 620-629, 2010.

32. Wang X, Chao L, Li X, Ma G, Chen L, Zang Y and Zhou G: Elevated expression of phosphorylated c-Jun NH2-terminal kinase in basal-like and 'triple-negative' breast cancers. Hum Pathol 41: 401-406, 2010.

33. Trancikova A, Mamais A, Webber PJ, Stafa K, Tsika E, Glauser L, West AB, Bandopadhyay R and Moore DJ: Phosphorylation of 4E-BP1 in the mammalian brain is not altered by LRRK2 expression or pathogenic mutations. PLoS One 7: e47784, 2012.

34. Kwon SH, Kim JA, Hong SI, Jung YH, Kim HC, Lee SY and Jang CG: Loganin protects against hydrogen peroxide-induced apoptosis by inhibiting phosphorylation of JNK, p38, and ERK 1/2 MAPKs in SH-SY5Y cells. Neurochem Int 58: 533-541, 2011.

35. Kim MK, Choi HS, Cho SG, Shin YC and Ko SG: Rubus coreanus Miquel extract causes apoptosis of doxorubicin-resistant NCI/ADR-RES ovarian cancer cells via JNK phosphorylation. Mol Med Rep 13: 4065-4072, 2016.

36. Wang L, Tian Z, Yang Q, Li H, Guan H, Shi B, Hou P and Ji M: Sulforaphane inhibits thyroid cancer cell growth and invasiveness through the reactive oxygen species-dependent pathway. Oncotarget 6: 25917-25931, 2015.

37. Guan H, Liang W, Liu J, Wei G, Li H, Xiu L, Xiao H and Li Y: Transmembrane protease serine 4 promotes thyroid cancer proliferation via CREB phosphorylation. Thyroid 25: 85-94, 2015.

38. Lu Y, Wei C and Xi Z: Curcumin suppresses proliferation and invasion in non-small cell lung cancer by modulation of MTA1-mediated Wnt/ $\beta$-catenin pathway. In Vitro Cell Dev Biol Anim 50: 840-850, 2014.
39. Sui C, Zhuang C, Sun D, Yang L, Zhang L and Song L: Notch1 regulates the JNK signaling pathway and increases apoptosis in hepatocellular carcinoma. Oncotarget 8: 45837-45847, 2017.

40. Husdal A, Bukholm G and Bukholm IR: The prognostic value and overexpression of cyclin $\mathrm{A}$ is correlated with gene amplification of both cyclin A and cyclin $\mathrm{E}$ in breast cancer patient. Cell Oncol 28: 107-116, 2006.

41. Romagosa C, Simonetti S, López-Vicente L, Mazo A, Lleonart ME, Castellvi J and Ramon y Cajal S: p16(Ink4a) overexpression in cancer: A tumor suppressor gene associated with senescence and high-grade tumors. Oncogene 30: 2087-2097, 2011.

42. Li Y, Shen L, Xu H, Pang Y, Xu Y, Ling M, Zhou J, Wang X and Liu Q: Up-regulation of cyclin D1 by JNK1/c-Jun is involved in tumorigenesis of human embryo lung fibroblast cells induced by a low concentration of arsenite. Toxicol Lett 206: 113-120, 2011.

43. Poomsawat S, Buajeeb W, Khovidhunkit SO and Punyasingh J: Alteration in the expression of cdk 4 and cdk6 proteins in oral cancer and premalignant lesions. J Oral Pathol Med 39: 793-799, 2010.

44. Schapansky J, Nardozzi JD and LaVoie MJ: The complex relationships between microglia, alpha-synuclein, and LRRK 2 in Parkinson's disease. Neuroscience 302: 74-88, 2015.

45. Berwick DC and Harvey K: LRRK2 signaling pathways: The key to unlocking neurodegeneration? Trends Cell Biol 21: 257-265, 2011.

46. Chen CY, Weng YH, Chien KY, Lin KJ, Yeh TH, Cheng YP, Lu CS and Wang HL: (G2019S) LRRK2 activates MKK4-JNK pathway and causes degeneration of SN dopaminergic neurons in a transgenic mouse model of PD. Cell Death Differ 19: 1623-1633, 2012.

47. Luerman GC, Nguyen C, Samaroo H, Loos P, Xi H, Hurtado-Lorenzo A, Needle E, Stephen Noell G, Galatsis P, Dunlop J, et al: Phosphoproteomic evaluation of pharmacological inhibition of leucine-rich repeat kinase 2 reveals significant off-target effects of LRRK-2-IN-1. J Neurochem 128: 561-576, 2014.

48. Moehle MS, Webber PJ, Tse T, Sukar N, Standaert DG, DeSilva TM, Cowell RM and West AB: LRRK2 inhibition attenuates microglial inflammatory responses. J Neurosci 32: 1602-1611, 2012

49. Prabhudesai S, Bensabeur FZ, Abdullah R, Basak I, Baez S, Alves G, Holtzman NG, Larsen JP and Møller SG: LRRK2 knockdown in zebrafish causes developmental defects, neuronal loss, and synuclein aggregation. J Neurosci Res 94: 717-735, 2016.

50. Xu P, Xia X, Yang Z, Tian Y, Di J and Guo M: Silencing of TCTN1 inhibits proliferation, induces cell cycle arrest and apoptosis in human thyroid cancer. Exp Ther Med 14: 3720-3726, 2017.

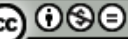

This work is licensed under a Creative Commons Attribution-NonCommercial-NoDerivatives 4.0 International (CC BY-NC-ND 4.0) License. 